\title{
Mapping 22q11.2 Gene Dosage Effects on Brain Morphometry
}

\author{
Amy Lin, ${ }^{1}$ Christopher R.K. Ching, ${ }^{1,2}$ Ariana Vajdi, ${ }^{1}$ Daqiang Sun, ${ }^{1}$ Rachel K. Jonas, ${ }^{1}{ }^{\oplus}$ Maria Jalbrzikowski, ${ }^{3}$ \\ Leila Kushan-Wells, ${ }^{1}$ Laura Pacheco Hansen, ${ }^{1}$ EEmma Krikorian, ${ }^{1}$ Boris Gutman, ${ }^{2}$ CDeepika Dokoru, ${ }^{1}$ \\ Gerhard Helleman, ${ }^{1}$ Paul M. Thompson, ${ }^{2}$ and $\mathbb{C}$ Carrie E. Bearden ${ }^{1,4}$ \\ ${ }^{1}$ Department of Psychiatry and Biobehavioral Sciences, Semel Institute for Neuroscience and Human Behavior, University of California at Los Angeles, Los \\ Angeles, California 90095, ${ }^{2}$ Imaging Genetics Center, Institute for Neuroimaging and Informatics, University of Southern California, Marina del Rey, \\ California 90292, ${ }^{3}$ Department of Psychiatry, University of Pittsburgh, Pittsburgh, Pennsylvania 15213, and ${ }^{4}$ Department of Psychology, University of \\ California at Los Angeles, Los Angeles, California 90095
}

Reciprocal chromosomal rearrangements at the 22q11.2 locus are associated with elevated risk of neurodevelopmental disorders. The 22q11.2 deletion confers the highest known genetic risk for schizophrenia, but a duplication in the same region is strongly associated with autism and is less common in schizophrenia cases than in the general population. Here we conducted the first study of 22q11.2 gene dosage effects on brain structure in a sample of 143 human subjects: 66 with 22q11.2 deletions (22q-del; 32 males), 21 with 22q11.2 duplications (22q-dup; 14 males), and 56 age- and sex-matched controls (31 males). 22q11.2 gene dosage varied positively with intracranial volume, gray and white matter volume, and cortical surface area (deletion $<$ control $<$ duplication). In contrast, gene dosage varied negatively with mean cortical thickness (deletion $>$ control $>$ duplication). Widespread differences were observed for cortical surface area with more localized effects on cortical thickness. These diametric patterns extended into subcortical regions: 22q-dup carriers had a significantly larger right hippocampus, on average, but lower right caudate and corpus callosum volume, relative to 22q-del carriers. Novel subcortical shape analysis revealed greater radial distance (thickness) of the right amygdala and left thalamus, and localized increases and decreases in subregions of the caudate, putamen, and hippocampus in 22q-dup relative to 22q-del carriers. This study provides the first evidence that 22q11.2 is a genomic region associated with gene-dose-dependent brain phenotypes. Pervasive effects on cortical surface area imply that this copy number variant affects brain structure early in the course of development.

Key words: autism spectrum disorder; chromosome 22; copy number variant; neurodevelopment; psychosis; structural neuroimaging

Significance Statement

Probing naturally occurring reciprocal copy number variation in the genome may help us understand mechanisms underlying deviations from typical brain and cognitive development. The 22q11.2 genomic region is particularly susceptible to chromosomal rearrangements and contains many genes crucial for neuronal development and migration. Not surprisingly, reciprocal genomic imbalances at this locus confer some of the highest known genetic risks for developmental neuropsychiatric disorders. Here we provide the first evidence that brain morphology differs meaningfully as a function of reciprocal genomic variation at the 22q11.2 locus. Cortical thickness and surface area were affected in opposite directions with more widespread effects of gene dosage on cortical surface area.

\section{Introduction}

Reciprocal chromosomal rearrangements represent powerful models to assess effects of copy number variation $(\mathrm{CNV})$ on brain morphology and associated neuropsychiatric outcomes. Gene dosage cannot be experimentally manipulated in humans as it can in animal or in vitro models, but a similar framework emerges initiative), including the National Institute of Biomedical Imaging and Bioengineering and National Cancer Institute. These funding sources had no further role in study design, in the collection, analysis, and interpretation of data, in the writing of the report, nor in the decision to submit the paper for publication. We thank the participants and their families for being a part of our research; Danielle Denneny and Khalima Bolden for conducting clinical assessments and administering neuropsychological measures to our participants; Giovanni Coppola for providing valuable support for qPCR and CNV breakpoint analysis; and Dmitry Isaev and Anjanibhargavi Ragothaman for contributing to the subcortical shape analysis pipeline. 
via naturally occurring genetic variation. Such genomic imbalances confer some of the highest genetic risk factors for prevalent developmental neuropsychiatric disorders (Malhotra and Sebat, 2012; Hoeffding et al., 2017) and offer a quasi-experimental "reverse genetics" approach to elucidate how genes may impact neurodevelopmental phenotypes (Hiroi et al., 2013).

The 22q11.2 locus is a valuable region to investigate gene dosage effects on brain development, as it is particularly susceptible to chromosomal rearrangements due to nonallelic homologous recombination (Stankiewicz and Lupski, 2002). Occurring at nearly 1 in 2000 live births (Grati et al., 2015), the 22q11.2 deletion (22q-del), also known as DiGeorge or Velocardiofacial syndrome (OMIM \#188400, \#192430), results from a $1.5-3 \mathrm{Mb}$ hemizygous deletion on the long arm of chromosome 22 (Shaikh et al., 2007). 22q-del is the largest known genetic risk factor for psychotic illness, associated with an $\sim 30$-fold increase in risk relative to population base rates (Bassett and Chow, 2008; Green et al., 2009; Schneider et al., 2014). It is also associated with heightened risk for other developmental neuropsychiatric disorders: attention deficit hyperactivity disorder, anxiety disorder, and autism spectrum disorders (ASDs) (Niklasson et al., 2001, 2009; Vorstman et al., 2006; Girirajan et al., 2011).

Duplications at the same locus (22q-dup) were first reported clinically in 2003 (Ensenauer et al., 2003). Unlike 22q-del, which tends to occur de novo, the duplication is frequently inherited (Ou et al., 2008). Less is known about the 22q-dup phenotype, which is highly variable (Wentzel et al., 2008), but it appears to be associated with elevated rates of ASD and delays in language and psychomotor development (Wenger et al., 2016). In an analysis of $>47,000$ individuals, the 22q-dup was significantly less common in schizophrenia cases than in the general population $(0.014 \%$ compared with $0.085 \%, \mathrm{OR}=0.17)$, suggesting the first putative protective mutation for schizophrenia (Rees et al., 2014). This finding of lower schizophrenia incidence in 22q-dup carriers compared with noncarriers has now been replicated in independent studies (Li et al., 2016; Rees et al., 2016; CNV and Schizophrenia Working Groups of the Psychiatric Genomics Consortium, Psychosis Endophenotypes International Consortium, 2017).

Genes within the 22q11.2 locus are essential for cortical circuit formation (Meechan et al., 2015a), so it is not surprising that 22q-del carriers show aberrations in cortical anatomy. These abnormalities include widespread reductions in cortical volume, particularly in midline regions, relative to typically developing controls (Bearden et al., 2007; Jalbrzikowski et al., 2013; Schmitt et al., 2015). Mouse models of 22q-del show diminished frequency of projection neurons in layers II/III of the medial prefrontal cortex, which was in turn associated with the severity of executive function deficits (Meechan et al., 2015b).

Although no study has yet characterized how a 22q11.2 duplication affects brain morphometry, dose-dependent effects on human brain structure have recently been discovered for other reciprocal CNVs associated with neuropsychiatric phenotypes. Stefansson et al. (2014) first demonstrated dose-dependent effects of genes within the 15q11.2 locus for measures of regional brain volume that overlap with regions affected in idiopathic

The authors declare no competing financial interests.

Correspondence should be addressed to Dr. Carrie E. Bearden, University of California at Los Angeles, Semel Institute for Neuroscience and Human Behavior, 760 Westwood Plaza, Room A7-436, Los Angeles, CA 90095. E-mail: CBearden@mednet.ucla.edu.

DOI:10.1523/JNEUROSCI.3759-16.2017

Copyright $\odot 2017$ the authors $\quad 0270-6474 / 17 / 376184-17 \$ 15.00 / 0$ psychosis. Similarly, reciprocal 16p11.2 deletions and duplications were found to have global, "mirror image" effects on brain structure, in which cortical surface area was differentially affected (Qureshi et al., 2014; Maillard et al., 2015).

We investigated cortical and subcortical anatomic variation at the $22 \mathrm{q} 11.2$ locus to test the hypothesis that reciprocal $22 \mathrm{q} 11.2$ deletions and duplications confer opposing effects on brain structure. We decomposed cortical volume into its constituent parts, cortical thickness (CT) and surface area (SA), which are thought to have distinct neurodevelopmental origins (Rakic, 1988; Panizzon et al., 2009; Winkler et al., 2010). Any differential effect of 22q11.2 variants on these measures may point to developmental processes that are disrupted during corticogenesis in distinct brain regions as a result of $22 \mathrm{q} 11.2$ gene dosage.

\section{Materials and Methods}

Participants. The sample consisted of 143 individuals: 66 with molecularly confirmed 22q11.2 deletions ( 32 males; 34 females), 21 with confirmed 22q11.2 duplications ( 14 males; 7 females), and 56 demographically matched, unrelated controls ( 31 males; 25 females; for demographics, see Table 1). Approximately $25 \%$ of the deletion carriers and controls were included in a prior publication (Jalbrzikowski et al., 2013). As such, the current study includes a substantially larger sample of 22q11.2 deletion carriers and controls, as well as a novel cohort of 22q11.2 duplication carriers. Patients were ascertained from either (1) the University of California at Los Angeles or Children's Hospital, Los Angeles Pediatric Genetics, Allergy/Immunology and/or Craniofacial Clinics, or (2) local support groups and websites. Demographically comparable typically developing comparison subjects were recruited from the same communities as patients via web-based advertisements and by posting flyers and brochures at local schools, pediatric clinics, and other community sites.

Exclusion criteria for all study participants included significant neurological or medical conditions (unrelated to 22q11.2 mutation) that might affect brain structure, history of head injury with loss of consciousness, insufficient fluency in English, and/or substance or alcohol abuse or dependence within the past 6 months. Healthy controls additionally could not have significant intellectual disability or meet criteria for any major mental disorder with the exception of attention deficit-hyperactivity disorder or a past episode of depression, based on information gathered during the Structured Clinical Interview for the Diagnostic and Statistical Manual of Mental Disorders, Ed 4 (First and Gibbon, 2004) and/or Computerized Diagnostic Interview for Children (Shaffer et al., 2000). All participants underwent a verbal and written informed consent process. Participants under the age of 18 years provided written assent, while their parent or guardian completed written consent. The University of California at Los Angeles Institutional Review Board approved all study procedures and informed consent documents.

Psychiatric and cognitive assessment. Supervised clinical psychology doctoral students administered neurocognitive and psychodiagnostic evaluations (Structured Clinical Interview for the Diagnostic and Statistical Manual of Mental Disorders/Computerized Diagnostic Interview for Children, as described above) to study participants. Estimates of general intellectual functioning were obtained for all participants using the Wechsler Abbreviated Scale of Intelligence (Wechsler, 1999) or Wechsler Adult Intelligence Scale, Ed 4 (Wechsler et al., 2008). Diagnosis of ASD was based on the Autism Diagnostic Observation Schedule (Lord et al., 2000) and the Autism Diagnostic Interview-Revised (Lord et al., 1994). To obtain dimensional measures of ASD-relevant behavior, parents of study participants also completed the Social Responsiveness Scale (Constantino and Gruber, 2007), a quantitative measure of reciprocal social behavior that has been extensively validated in both clinically ascertained and population-based samples and the Repetitive Behavioral Scale (Lam and Aman, 2007) to capture patterns of restricted repetitive behavior often observed in ASD.

All diagnoses were determined by trained clinicians who participated in an ongoing quality assurance program (Ventura et al., 1998). Training, reliability, and ongoing quality assurance procedures for psychodiagnostic assessments are detailed in prior publications (Jalbrzikowski et al., 2013, 2016). 
Table 1. Participant demographics ${ }^{a}$

\begin{tabular}{|c|c|c|c|}
\hline & 22q11.2 deletion participants $(N=66)$ & Healthy control participants $(N=56)$ & $22 q 11.2$ duplication participants $(N=21)$ \\
\hline Scanner & $34 \mathrm{BMC}, 32 \mathrm{CCN}$ & $27 \mathrm{BMC}, 29 \mathrm{CCN}$ & $21 \mathrm{CCN}$ \\
\hline Age (SD) & $15.7(7.55)$ & $14.6(6.93)$ & $16.8(12.00)$ \\
\hline Males (\% male) & $32(48.5 \%)$ & $31(55.4 \%)$ & $14(66.7 \%)$ \\
\hline $\operatorname{Race}^{*}, \dagger(\%)$ & $\begin{array}{l}59 \text { white }(89.4 \%), 1 \text { black }(1.5 \%), \\
6 \text { multirace }(9.1 \%)\end{array}$ & $\begin{array}{l}33 \text { white }(58.9 \%), 7 \text { black (12.5\%), } 5 \text { Asian (8.9\%), } \\
11 \text { multirace (19.6\%) }\end{array}$ & 21 white (100\%) \\
\hline Full-Scale IQ ${ }^{*},{ }^{* *}, \dagger(S D)$ & $78.68(12.53)$ & $111.5(18.98)$ & $96.15(20.42)$ \\
\hline Verbal IQ****,† (SD) & $76.2(8.99)$ & $113.3(13.15)$ & $93.3(13.96)$ \\
\hline Nonverbal IQ**, $†(S D)$ & $80.6(10.91)$ & $105(10.11)$ & $98.7(14.41)$ \\
\hline Highest parental education, years ${ }^{* *}(S D)$ & $16.26(2.52)$ & $15.7(3.18)$ & $15.0(2.25)$ \\
\hline $\operatorname{ASD}(\%)^{*}, \dagger$ & $29(43.9 \%)$ & 0 & $13(61.9 \%)$ \\
\hline Psychotic disorder $(\%)^{* *}, \dagger$ & $4(6.1 \%)$ & 0 & 0 \\
\hline $\operatorname{ADHD}(\%)^{*}, \dagger$ & $27(40.9 \%)$ & $2(3.6 \%)$ & $6(28.6 \%)$ \\
\hline Social Responsiveness Scale ${ }^{*}, \dagger($ SD) & $70.07(14.84)$ & $49.29(13.58)$ & $72.31(16.89)$ \\
\hline Repetitive Behavioral Scale ${ }^{*}, \dagger$ (SD) & $16.84(22.77)$ & $2.88(7.16)$ & $16.11(19.44)$ \\
\hline \multicolumn{4}{|l|}{ Current medication } \\
\hline Psychostimulant ${ }^{* * *}(\%)$ & $6(9.1 \%)$ & $1(1.8 \%)$ & $6(28.6 \%)$ \\
\hline Antipsychotict (\%) & $7(10.6 \%)$ & 0 & $1(4.8 \%)$ \\
\hline Antidepressant (SSRI) ${ }^{* *}, \dagger(\%)$ & $11(16.7 \%)$ & 0 & $1(4.8 \%)$ \\
\hline Other (\%) & $4(6.1 \%)$ & $1(1.8 \%)$ & $2(9.52 \%)$ \\
\hline None $^{*}, \dagger(\%)$ & $38(57.6 \%)$ & $52(92.9 \%)$ & $12(57.1 \%)$ \\
\hline \multicolumn{4}{|l|}{ CNV breakpoints } \\
\hline$A-B(\%)$ & $5(7.6 \%)$ & - & $5(23.8 \%)$ \\
\hline $\mathrm{A}-\mathrm{C}(\%)$ & $1(1.5 \%)$ & - & - \\
\hline$A-D(\%)$ & $56(84.8 \%)$ & - & $10(47.6 \%)$ \\
\hline B-D (\%) & - & - & $3(14.3 \%)$ \\
\hline C-E (\%) & $1(1.5 \%)$ & - & $1(4.8 \%)$ \\
\hline Other (\%) & $3(4.5 \%)$ & - & $2(9.5 \%)$ \\
\hline
\end{tabular}

${ }^{a}$ BMC, Brain Mapping Center; CCN, Center for Cognitive Neuroscience. One 22q-dup carrier was taking both an antipsychotic and psychostimulant. Family relatedness of the 22q-dup cohort: 4 singletons, 5 families with 2 members (3 parent-child pairs, 2 sibling pairs), 1 family with 3 members (siblings), 1 family with 4 members (1 parent, 3 children). CNV breakpoints: A-C deletion has additional C-D duplication, 3 Other deletions include D-F, D-G, and PRODH/DGCR8, 2 Other duplications include F-H and TOP3B. Data not available for the following: Full-Scale IQ/Verbal IQ: 1 22q-del, 2 controls, and 122 -dup; Nonverbal IQ; 2 controls and 122 -dup; Parental Education: 5 22q-del; Social Responsiveness Scale: $522 q$-dup, $622 q$-del, and 18 controls; Repetitive Behavioral Scale: 322 -del, 4 controls, and 2 22q-dup; Medication information for 2 controls.

*22q-dup/control difference (pairwise significance at uncorrected $p<0.05$ ).

**22q-dup/22q-del difference (pairwise significance at uncorrected $p<0.05$ ).

$+22 q$-del/control difference (pairwise significance at uncorrected $p<0.05$ ).

$q R T-P C R$. As an initial proof of principle to determine whether duplication and deletion carriers showed the expected increases or decreases, respectively, in gene dosage, we first investigated gene expression levels for three key genes in the 22q11.2 locus. Peripheral blood samples were drawn in two PAXgene tubes and were stored at $4^{\circ} \mathrm{C}$. RNA was extracted using the PAXgene blood RNA kit (PreAnalytix, QIAGEN). We assessed RNA quantity using Nanodrop ND-1000 spectrophotometer (Nanodrop Technologies) and also quality with Agilent Bioanalyzer Nanochips.

qRT-PCR was conducted using TaqMan assays, as described by Coppola et al. (2006). Total RNA was converted into cDNA by SuperScript II kit (Invitrogen). The reactions were performed with a TaqMan Master Mix (Bio-Rad) in a $25 \mu$ l volume. Assays were performed in triplicate and analyzed using a Roche Lightcycler. qPCR analyses were performed using the 2(-Delta Delta $\mathrm{C}(\mathrm{T}))$ method $(2-\Delta \Delta \mathrm{Ct})$. We assayed three genes within the 22q11.2 locus: catechol-O-methyltransferase (comt), DiGeorge Syndrome Critical Region Gene 8 (dgcr8), and Zinc Finger DHHC-Type Containing $8(z d h h c 8)$, using gapdh as a reference gene. Additionally, all 22q11.2 CNV carriers underwent multiplex ligation-dependent probe amplification (MLPA) (Sørensen et al., 2010) to determine specific breakpoint locations (Table 1).

MRI acquisition and preprocessing. Measures of brain structure were obtained with high-resolution structural MRI. Scanning was conducted on an identical 3 tesla Siemens Trio MRI scanner with a 12-channel head coil at the University of California at Los Angeles Brain Mapping Center or at the Center for Cognitive Neuroscience (Table 1). Each scan began with a $10 \mathrm{~min}$ acquisition of standard images used for determining regional anatomy, including a sagittal localizer image $(\mathrm{TR} / \mathrm{TE}=500 / 33$ ms, $192 \times 256$ matrix), a high-resolution T2-weighted axial image (TR/ $\mathrm{TE}=5000 / 33 \mathrm{~ms}, 128 \times 128$ matrix, FOV $=200 \times 200 \mathrm{~mm}$ ), and a sagittal $1 \mathrm{~mm}^{3} \mathrm{~T} 1$-weighted image. We used FreeSurfer to process $1 \mathrm{~mm}^{3}$ T1-weighted anatomical images acquired with an MPRAGE sequence.
The parameters for the MPRAGE were the following: $\mathrm{TR}=2.3 \mathrm{~s}$, TE $=$ $2.91 \mathrm{~ms}, \mathrm{FOV}=256 \mathrm{~mm}$, matrix $=240 \times 256$, flip angle $=9^{\circ}$, slice thickness $=1.20 \mathrm{~mm}, 160$ slices. The FreeSurfer image analysis suite (version 5.3.0; http://surfer.nmr.mgh.harvard.edu) surface-based processing pipeline was used to derive measures of volume, cortical thickness, and surface area. FreeSurfer is a well-validated processing package that has been previously described in detail (Dale et al., 1999; Fischl et al., 1999). We extracted cortical measures based on the Desikan FreeSurfer atlas (Desikan et al., 2006).

Quality assessment of MRI. Structural T1-weighted MRI brain scans were analyzed in an unbiased, whole-brain approach using well-validated analysis and quality control protocols developed for the ENIGMA consortium (Enhancing Neuroimaging Genetics through Meta-Analysis) (Thompson et al., 2014), which have previously been applied in large-scale studies of major depression (Schmaal et al., 2016), bipolar disorder (Hibar et al., 2016), and schizophrenia (van Erp et al., 2016). We used the ENIGMA quality assessment pipeline (Thompson et al., 2017) to determine scan quality. Segmented regions were visually inspected and statistically evaluated for outliers following standardized ENIGMA protocols (http:// enigma.ini.usc.edu/protocols/imaging-protocols). Briefly, the pipeline includes three major steps: (1) extracting and organizing brain measures from FreeSurfer, (2) quality checking the outputs wherein a set of representative cross-sections from each subject are displayed with colored FreeSurfer segmentations, and (3) calculating population summary statistics of the cortical traits and related histograms. Visual inspections of ENIGMA snapshots were completed by 3 separate individuals who were blind to diagnostic status. Scans of $422 \mathrm{q}$-dup participants, 3 control participants, and $522 \mathrm{q}$-del participants failed the initial quality control assessment. The 22q-dup participant scans were then manually edited using standard procedures (detailed in Jalbrzikowski et al., 2013), after which they passed QC assessment. 

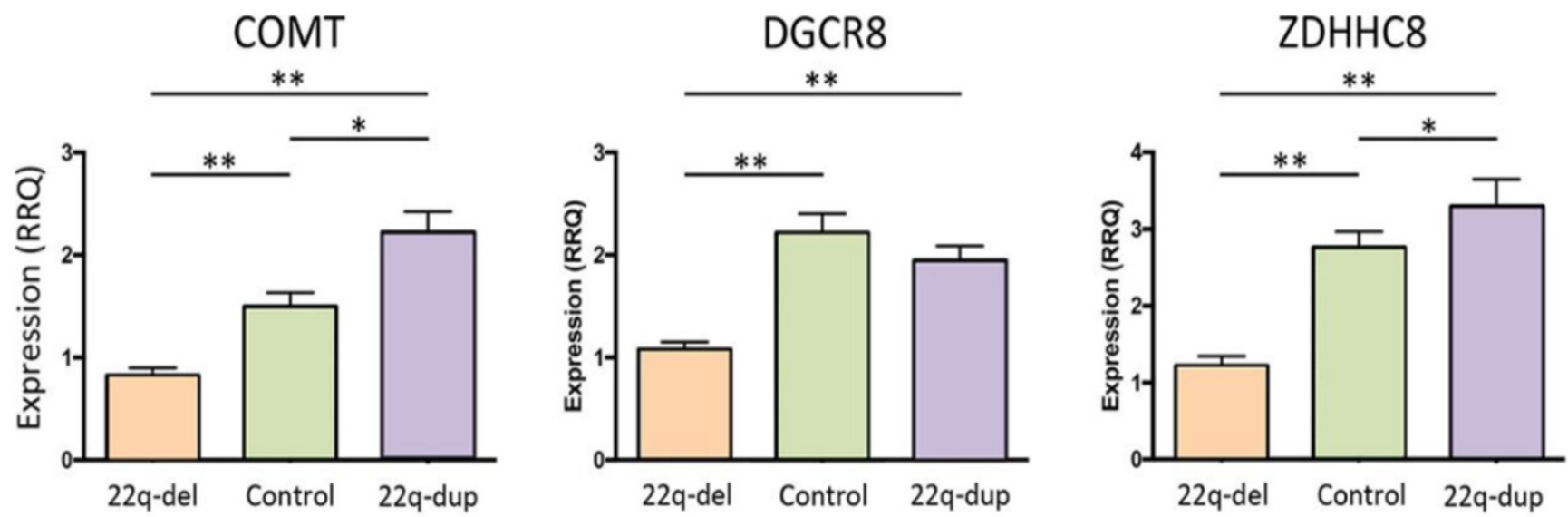

Figure 1. Gene expression. Relative Relative Quantification (RRQ) levels of comt, dgcr8, and zdhhc8. comt and zdhhc8 expression levels were significantly different between all three cohorts, whereas dgcr8 expression only showed significant differences between 22q-del carriers and controls as well as 22q-del carriers and 22q-dup carriers. ${ }^{*} p<0.03$. ${ }^{* *} p<0.001$.
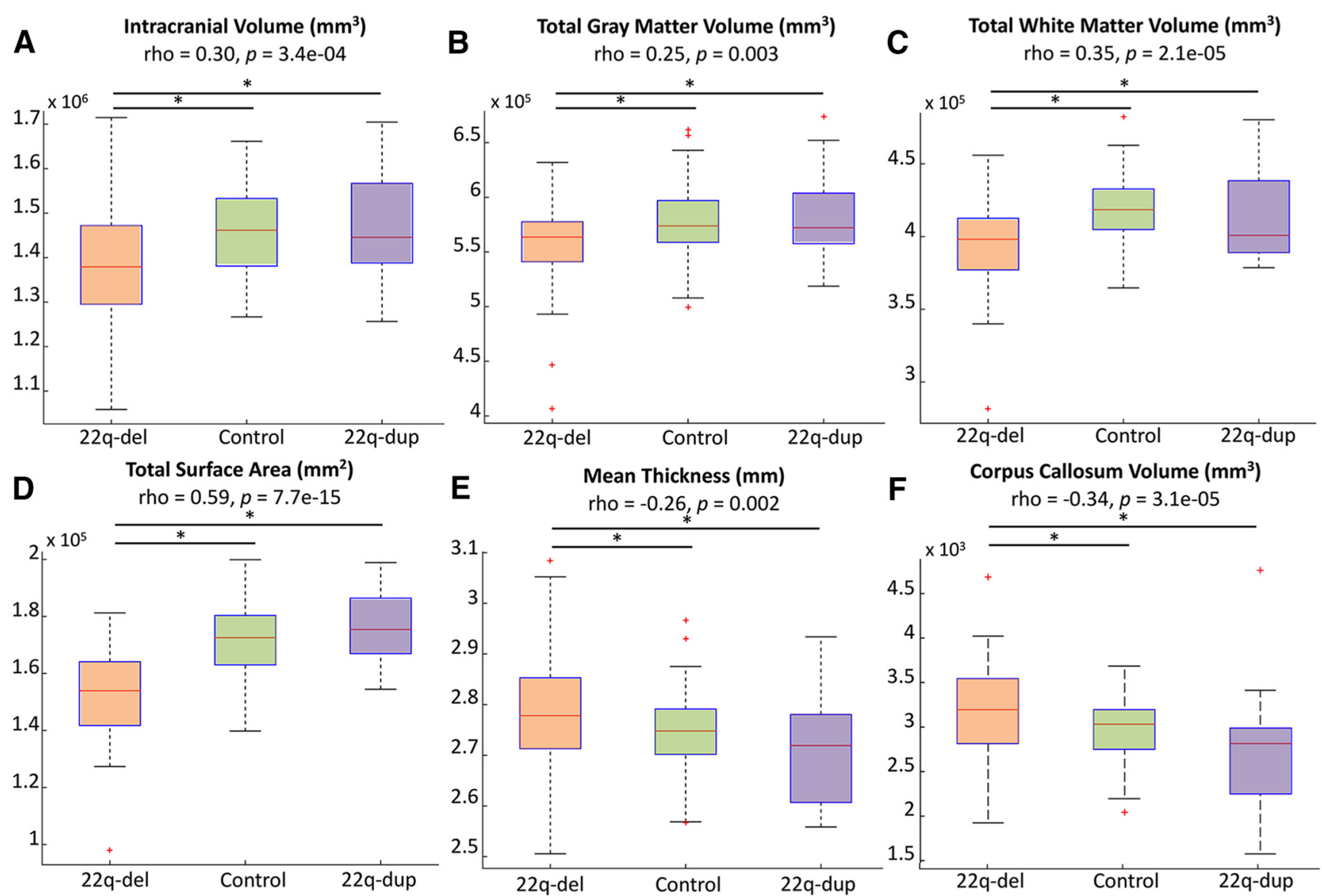

Figure 2. Global brain metrics for intracranial volume, total gray matter volume, total white matter volume, total surface area (SA), mean cortical thickness (CT), and corpus callosum volume. Boxplots of global brain metrics for each individual across groups adjusted for sex, age, and scanner location (as well as intracranial volume for volumetric measures). Spearman nonparametric correlations were performed for each measure, indicating significant gene dosage effects. For all measures, there were significant pairwise differences between $22 q$-del and controls that survive post hoc correction. ${ }^{*} p<0.05$.

Subcortical shape analysis. As conventional subcortical volume analysis may obscure fine-grained differences in anatomical changes, a novel surface-based high-resolution parametric mapping technique was used to investigate shape differences across subjects for all subcortical regions of interest (ROIs) (Mamah et al., 2016). This technique is sensitive to subtle volumetric variations (Gutman et al., 2012, 2015) that may represent underlying subfield organization (Wang et al., 2008). It has recently shown high vertexwise heritability, suggesting that shape indexes a biologically valid phenotype (Roshchupkin et al., 2016). A growing body of evidence indicates that different diseases have distinct effects on hippocampal subfields (Small et al., 2011); these localized patterns of disease effects may extend to other subcortical structures as well.

Using FreeSurfer segmentations as an initial input for creating the shape models, shape registration was based on existing shape templates and template "medial" models. The shape template was 
Table 2. Global metrics: adjusted means, SEs, percentage difference from controls, and estimated 22q-dupN ${ }^{a}$

\begin{tabular}{|c|c|c|c|c|c|c|c|}
\hline Region & $F$ & 22q-del Mean (SE) & $\begin{array}{l}22 q \text {-del \% difference } \\
\text { from controls }\end{array}$ & $\begin{array}{l}\text { Control, } \\
\text { mean (SE) }\end{array}$ & $\begin{array}{l}\text { 22q-dup, } \\
\text { mean (SE) }\end{array}$ & $\begin{array}{l}\text { 22q-dup \% difference } \\
\text { from controls }\end{array}$ & dupN \\
\hline Corpus callosum volume $\mathrm{e}^{* *}, \mathrm{t}, \mathrm{t}+$ & 7.3 & $3195.5(60.7)$ & $7.6 \%$ & $2969.3(64.4)$ & $2723.9(113.5)$ & $-8.3 \%$ & 216 \\
\hline Cortical white matter volume $\mathrm{e}^{* *}, \mathrm{t}, \mathrm{t}+$ & 11.9 & $395,129.2(3381.3)$ & $-5.7 \%$ & $418,977.0(3587.9)$ & $415,362.7(6319.3)$ & $-0.9 \%$ & 695 \\
\hline Total gray matter**,,,$+ \dagger$ & 5.4 & $556,341.5(4785.5)$ & $-3.7 \%$ & $577,545.6(5080.0)$ & $581,072.5(8947.3)$ & $0.6 \%$ & $>1000$ \\
\hline Mean thickness** $, \dagger, \dagger \dagger$ & 4.6 & $2.78(0.01)$ & $1.5 \%$ & $2.74(0.01)$ & $2.71(0.02)$ & $-1.1 \%$ & 140 \\
\hline Total intracranial volume ${ }^{* *}, \mathrm{t}, \mathrm{t}$ & 7.1 & $1385812.3(14058.4)$ & $-4.9 \%$ & $1,456,843.0(15317.2)$ & $1,466,356.0(27086.6)$ & $0.7 \%$ & 403 \\
\hline Total area**,, , †† & 35.4 & $152,415.5(1760.0)$ & $-11.1 \%$ & $171,524.8(1917.5)$ & $176,466.1(3390.9)$ & $2.9 \%$ & 208 \\
\hline
\end{tabular}

${ }^{a}$ Adjusted means are covaried for age, sex, and scanner location, as well as intracranial volume for volumetric measures.

**Survives FDR correction ( $p<0.05$ threshold) at post hoc level for 22q-dup versus 22q-del.

tSurvives FDR correction ( $p<0.05$ threshold) at post hoc level for $22 q$-del versus control.

ttSurvives FDR correction ( $p<0.05$ threshold) at omnibus level.

Table 3. Regional cortical thickness adjusted means, and SEs ${ }^{a}$

\begin{tabular}{|c|c|c|c|c|c|c|c|c|c|}
\hline Region & $F$ & $\begin{array}{l}\text { 22q-del, } \\
\text { mean (SE) }\end{array}$ & $\begin{array}{l}\text { Control, } \\
\text { mean (SE) }\end{array}$ & $\begin{array}{l}\text { 22q-dup, } \\
\text { mean (SE) }\end{array}$ & Region & $F$ & $\begin{array}{l}\text { 22q-del, } \\
\text { mean (SE) }\end{array}$ & $\begin{array}{l}\text { Control, } \\
\text { mean (SE) }\end{array}$ & $\begin{array}{l}\text { 22q-dup, } \\
\text { mean (SE) }\end{array}$ \\
\hline Left hemisphere & & & & & Right hemisphere & & & & \\
\hline Bank of superior temporal sulcus & 2.4 & $2.65(0.02)$ & $2.70(0.02)$ & $2.75(0.04)$ & Bank of superior temporal sulcus & 0.8 & $2.83(0.02)$ & $2.85(0.03)$ & $2.89(0.04)$ \\
\hline Caudal anterior cingulate gyrus & 4.8 & $2.83(0.03)$ & $2.95(0.04)$ & $3.03(0.07)$ & Caudal anterior cingulate gyrus & 2.7 & $2.70(0.03)$ & $2.82(0.04)$ & $2.78(0.07)$ \\
\hline Caudal middle frontal gyrus, ${ }^{* *}, \mathrm{t}$ & 18.2 & $2.82(0.02)$ & $2.74(0.02)$ & $2.58(0.04)$ & Caudal middle frontal gyrus ${ }^{* *},+\dagger$ & 12.7 & $2.75(0.02)$ & $2.66(0.02)$ & $2.55(0.04)$ \\
\hline Cuneus & 3.3 & $2.13(0.02)$ & $2.05(0.03)$ & $2.04(0.04)$ & Cuneus & 3.6 & $2.17(0.02)$ & $2.11(0.02)$ & $2.05(0.04)$ \\
\hline Entorhinal cortex & 1.6 & $3.48(0.04)$ & $3.55(0.05)$ & $3.38(0.09)$ & Entorhinal cortex & 1.5 & $3.81(0.05)$ & $3.80(0.05)$ & $3.63(0.09)$ \\
\hline Frontal pole & 0.4 & $2.84(0.04)$ & $2.89(0.05)$ & $2.88(0.09)$ & Frontal pole & 0.8 & $2.83(0.04)$ & $2.76(0.05)$ & $2.84(0.08)$ \\
\hline Fusiform gyrus & 0.2 & $2.90(0.02)$ & $2.90(0.02)$ & $2.88(0.03)$ & Fusiform gyrus & 2.2 & $3.00(0.02)$ & $2.95(0.02)$ & $2.98(0.03)$ \\
\hline Inferior parietal cortex & 1.7 & $2.70(0.02)$ & $2.69(0.02)$ & $2.64(0.03)$ & Inferior parietal cortex & 3.4 & $2.74(0.02)$ & $2.70(0.02)$ & $2.64(0.03)$ \\
\hline Inferior temporal gyrus & 0.0 & $2.88(0.02)$ & $2.88(0.03)$ & $2.88(0.05)$ & Inferior temporal gyrus & 1.0 & $3.05(0.02)$ & $3.01(0.02)$ & $3.03(0.04)$ \\
\hline Insula** ${ }^{*}$, ,†† & 23.3 & $3.42(0.02)$ & $3.25(0.02)$ & $3.21(0.04)$ & Insula†,†† & 7.5 & $3.42(0.02)$ & $3.30(0.02)$ & $3.29(0.04)$ \\
\hline Isthmus cingulate & 1.7 & $2.78(0.03)$ & $2.76(0.03)$ & $2.67(0.05)$ & Isthmus cingulate gyrus & 0.8 & $2.65(0.02)$ & $2.68(0.03)$ & $2.61(0.05)$ \\
\hline Lateral occipital cortex & 0.8 & $2.35(0.02)$ & $2.33(0.02)$ & $2.30(0.03)$ & Lateral occipital cortex & 1.4 & $2.42(0.02)$ & $2.41(0.02)$ & $2.36(0.03)$ \\
\hline Lateral orbitofrontal cortex & 2.8 & $2.91(0.02)$ & $2.83(0.03)$ & $2.86(0.04)$ & Lateral orbitofrontal cortex & 2.1 & $2.76(0.02)$ & $2.70(0.03)$ & $2.80(0.05)$ \\
\hline Lingual gyrus ${ }^{* *},+\dagger$ & 9.9 & $2.30(0.02)$ & $2.23(0.02)$ & $2.16(0.03)$ & Lingual gyrus ${ }^{* *}, \dagger \dagger$ & 8.3 & $2.38(0.02)$ & $2.29(0.02)$ & $2.24(0.04)$ \\
\hline Medial orbitofrontal cortex & 6.7 & $2.70(0.03)$ & $2.57(0.03)$ & $2.52(0.06)$ & Medial orbitofrontal cortex & 6.1 & $2.55(0.03)$ & $2.43(0.03)$ & $2.39(0.05)$ \\
\hline Middle temporal gyrus & 0.7 & $3.05(0.02)$ & $3.02(0.02)$ & $3.04(0.04)$ & Middle temporal gyrus & 2.3 & $3.15(0.02)$ & $3.08(0.03)$ & $3.09(0.05)$ \\
\hline Paracentral cortex†, †† & 7.6 & $2.66(0.02)$ & $2.55(0.02)$ & $2.53(0.04)$ & Paracentral gyrus ${ }^{* *},+\dagger$ & 8.9 & $2.70(0.02)$ & $2.62(0.02)$ & $2.51(0.04)$ \\
\hline Parahippocampal gyrus** ${ }^{*}, \mathrm{t}, \dagger$ & 13.0 & $2.70(0.04)$ & $2.94(0.04)$ & $3.02(0.07)$ & Parahippocampal gyrus & 0.7 & $2.95(0.04)$ & $3.01(0.04)$ & $2.99(0.07)$ \\
\hline Pars opercularis** $, \dagger, \uparrow \dagger$ & 15.2 & $2.89(0.02)$ & $2.77(0.02)$ & $2.75(0.03)$ & Pars opercularis & 3.3 & $2.82(0.02)$ & $2.73(0.03)$ & $2.73(0.04)$ \\
\hline Pars orbitalis & 5.4 & $3.00(0.03)$ & $2.90(0.03)$ & $2.81(0.06)$ & Pars orbitalis & 2.1 & $2.83(0.03)$ & $2.73(0.04)$ & $2.78(0.07)$ \\
\hline Pars triangularis ${ }^{* *}, \dagger, \mathrm{,} \dagger$ & 14.2 & $2.76(0.02)$ & $2.61(0.02)$ & $2.56(0.04)$ & Pars triangularis & 2.9 & $2.64(0.03)$ & $2.53(0.03)$ & $2.55(0.06)$ \\
\hline Pericalcarine gyrus & 5.4 & $1.85(0.02)$ & $1.78(0.02)$ & $1.71(0.04)$ & Pericalcarine gyrust, & 9.7 & $1.87(0.02)$ & $1.75(0.02)$ & $1.72(0.04)$ \\
\hline Postcentral gyrus & 6.8 & $2.28(0.02)$ & $2.19(0.02)$ & $2.17(0.04)$ & Postcentral gyrus & 5.3 & $2.28(0.02)$ & $2.20(0.02)$ & $2.14(0.04)$ \\
\hline Posterior cingulate gyrus & 0.0 & $2.79(0.02)$ & $2.79(0.02)$ & $2.79(0.04)$ & Posterior cingulate gyrus & 2.9 & $2.72(0.02)$ & $2.78(0.02)$ & $2.72(0.04)$ \\
\hline Precentral gyrus ${ }^{* *}, \dagger \dagger$ & 9.9 & $2.76(0.02)$ & $2.70(0.02)$ & $2.61(0.03)$ & Precentral gyrus & 6.2 & $2.73(0.02)$ & $2.65(0.02)$ & $2.60(0.04)$ \\
\hline Precuneus & 4.4 & $2.67(0.02)$ & $2.63(0.02)$ & $2.56(0.03)$ & Precuneus*,**, & 11.3 & $2.70(0.02)$ & $2.66(0.02)$ & $2.50(0.04)$ \\
\hline Rostral anterior cingulate gyrus & 0.6 & $3.18(0.04)$ & $3.14(0.04)$ & $3.10(0.07)$ & Rostral anterior cingulate gyrus & 1.9 & $2.83(0.03)$ & $2.92(0.03)$ & $2.92(0.06)$ \\
\hline Rostral middle frontal gyrus ${ }^{* *},{ }^{\prime} \dagger$ & 10.3 & $2.64(0.02)$ & $2.54(0.02)$ & $2.46(0.04)$ & Rostral middle frontal gyrus ${ }^{* *}, \dagger, \dagger \dagger$ & 9.4 & $2.46(0.02)$ & $2.35(0.02)$ & $2.29(0.04)$ \\
\hline Superior frontal gyrus ${ }^{*},{ }^{* *}, \mathrm{t \dagger}$ & 14.7 & $3.05(0.02)$ & $3.00(0.02)$ & $2.84(0.04)$ & Superior frontal gyrus ${ }^{* *},+\dagger$ & 10.1 & $2.93(0.02)$ & $2.88(0.02)$ & $2.74(0.04)$ \\
\hline Superior parietal cortex & 2.7 & $2.41(0.02)$ & $2.37(0.02)$ & $2.32(0.04)$ & Superior parietal cortex & 3.4 & $2.40(0.02)$ & $2.34(0.02)$ & $2.30(0.04)$ \\
\hline Superior temporal gyrus & 5.9 & $2.90(0.02)$ & $3.00(0.02)$ & $2.97(0.04)$ & Superior temporal gyrus & 0.2 & $2.99(0.02)$ & $2.99(0.02)$ & $3.02(0.04)$ \\
\hline Supramarginal gyrus ${ }^{* *}, \dagger \dagger$ & 9.0 & $2.86(0.02)$ & $2.77(0.02)$ & $2.71(0.04)$ & Supramarginal gyrus**,, , & 15.0 & $2.90(0.02)$ & $2.79(0.02)$ & $2.70(0.04)$ \\
\hline Temporal pole & 0.3 & $3.70(0.04)$ & $3.68(0.05)$ & $3.74(0.08)$ & Temporal pole & 0.3 & $3.92(0.04)$ & $3.91(0.05)$ & $3.84(0.08)$ \\
\hline Transverse temporal gyrus & 0.5 & $2.58(0.03)$ & $2.62(0.03)$ & $2.57(0.05)$ & Transverse temporal gyrus & 1.8 & $2.68(0.03)$ & $2.60(0.03)$ & $2.68(0.06)$ \\
\hline
\end{tabular}

${ }^{a}$ Adjusted means are covaried for age, sex, and scanner location.

*Survives FDR correction ( $p<0.05$ threshold) at post hoc level for 22q-dup versus control.

**Survives FDR correction ( $p<0.05$ threshold) at post hoc level for 22q-dup versus 22q-del.

tSurvives FDR correction ( $p<0.05$ threshold) at post hoc level for 22q-del versus control.

ttSurvives FDR correction ( $p<0.05$ threshold) at omnibus level.

made by registering all subjects to a representative subject. The Euclidean average of these shapes served as the template surface, from which the template medial curve was computed. A pointwise measure of shape morphometry, radial distance, was derived for all 14 subcortical ROIs for each subject, using a medial model approach (Gutman et al., 2012, 2015). For each point $\boldsymbol{p} \in \mathcal{M}$ on the surface, and given a medial curve $\boldsymbol{c}:[0, \mathbf{1}] \rightarrow \mathbb{R}^{3}$, the radial distance is defined by the following:

$$
D(\boldsymbol{p})=\min \{\|\boldsymbol{c}(t)-\boldsymbol{p}\| t \in[0,1]\}
$$

In this way, radial distance (termed "thickness" henceforth) was calculated in native space for up to 2500 homologous points across each subcortical structure, providing a detailed index of regional shape differences across subjects. We included only those shape models that passed visual inspection and conformed to T1-weighted MRI anatomical 


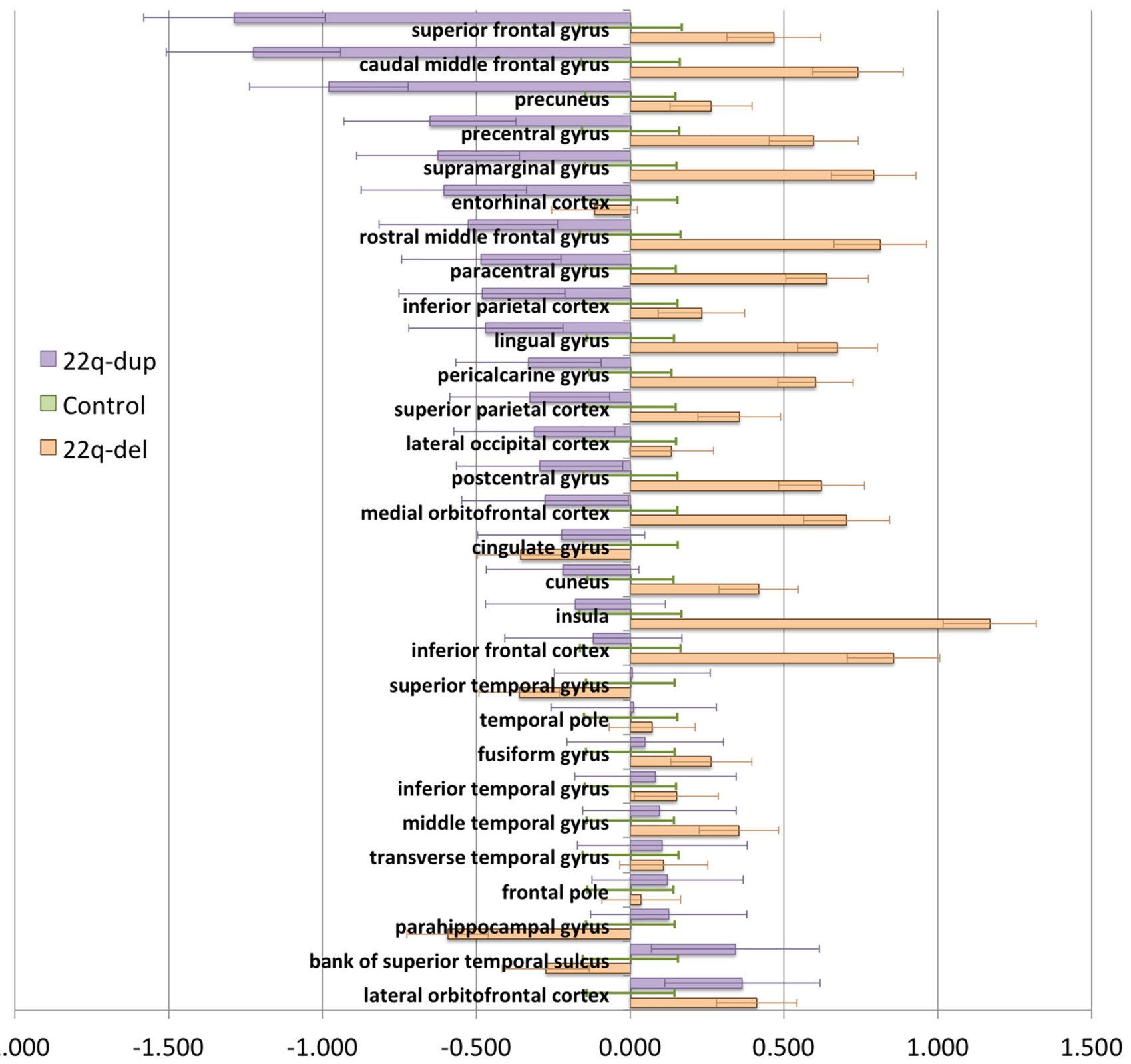

Figure 3. Cortical thickness.zscore plots of estimated marginal mean \pm SE. zscores are derived from individual subject means adjusted for sex, age, and scanner location using control mean and SD for each region. Then, $z$ scores were submitted to the same primary statistical analysis to generate estimated marginal mean \pm SE. 22q-dup showed lower thickness relative to $22 q$-del patients in predominantly medial frontal and parietal regions, with controls showing an intermediate pattern.

boundaries using the ENIGMA Shape Analysis Quality Assessment Protocol (http://enigma.ini.usc.edu/protocols/imaging-protocols/).

Statistical analysis. The primary statistical analyses were performed in SPSS software version 24 (IBM; RRID: SCR_002865). Additional demographic comparisons and effect size calculations were done in either MATLAB version R2015a (The MathWorks; RRID: SCR_001622) or R 3.0.2 (R Core Team, 2016; RRID: SCR_000432). Statistical modeling for shape analyses was performed using the R stats package (https://stat.ethz. $\mathrm{ch} / \mathrm{R}-\mathrm{manual} / \mathrm{R}$-devel/library/stats/html/lm.html). We conducted independent samples $t$ tests for continuous variables and $\chi^{2}$ tests for categorical variables. For the analyses of relative gene expression differences, we conducted separate univariate ANCOVAs with gene expression level as the dependent variable, CNV status as the independent variable, and age, gender, and qRT-PCR batch as covariates.

Significance testing for our primary analyses was conducted in two steps. First, we determined whether 22q11.2 CNVs had an effect on standard FreeSurfer ROIs for CT and SA, as well as volumes of subcortical structures and global brain metrics (total intracranial volume, total gray, and white matter volume, total SA, and average CT). For this omnibus test, we performed an ANCOVA and false discovery rate (FDR) correction at $q=0.05$ (Benjamini and Hochberg, 1995) for the number of regions, for each brain metric. Group (22q-dup, 22q-del, or control) was used as the independent variable, and each ROI was included as the dependent variable with age, sex, and scanner location as covariates. Analyses of cortical and subcortical volume included intracranial volume (ICV) as an additional covariate. Given the considerable variance across different brain structures, we performed an ANCOVA for each ROI independently. Second, for regions that passed the FDR-corrected omnibus test, we conducted post hoc tests for each pairwise comparison, applying the same correction used for the initial omnibus test.

For subcortical shape analyses, a multiple linear regression model was used to assess surface-based thickness differences between 22q-del carriers, 22q-dup carriers, and controls after correcting for age, sex, ICV, and scanner location. The model was fitted at each point across the surface of each subcortical structure. As these values were calculated in native space, ICV was included as a covariate to regress out effects of head 


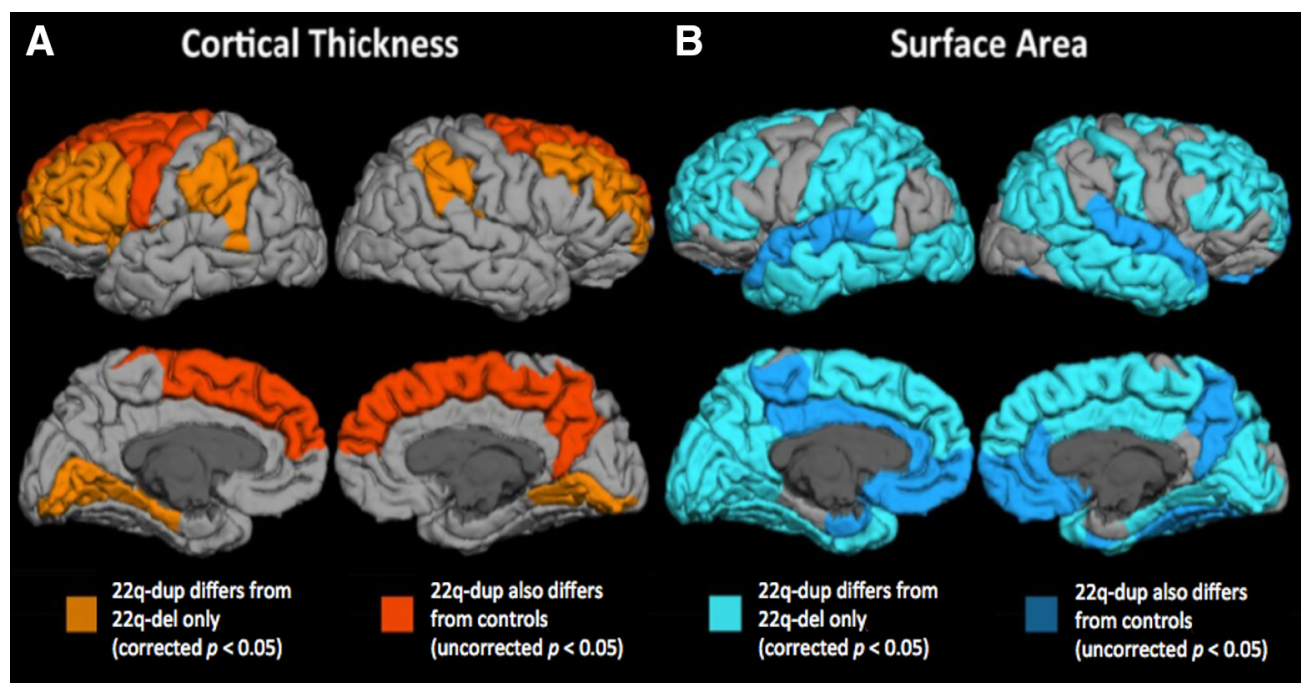

Figure 4. Neuroanatomic differences between 22q-dup carriers, 22q-del carriers, and controls. Cortical thickness and surface area. A, Light orange represents regions in which 22q-dup shows significant differences in cortical thickness relative to 22q-del (FDR-corrected, $q<0.05$ ). Dark orange represents regions in which 22q-dup significantly differs from both 22q-del (corrected) and controls (uncorrected, nominal $p<0.05$ ), with 22q-dup showing lower thickness relative to 22q-del and controls in frontal, inferior parietal, and parahippocampal regions. $B$, Light blue represents regions in which 22q-dup carriers differ in surface area from 22q-del carriers (FDR-corrected, $q<0.05$ ). Dark blue represents regions where 22q-dup differs significantly from both 22q-del (corrected) and controls (uncorrected, nominal $p<$ 0.05). 22q-dup carriers show greater surface area relative to 22q-del carriers and controls throughout most of the cortex, except for lateral orbitofrontal, middle frontal, inferior parietal, and right occipital regions.

size. To correct for multiple comparisons, a standard FDR correction was again applied at $q=0.05$. Statistical models were fitted for the following comparisons of interest: 22q-del carriers versus controls, $22 \mathrm{q}$-dup carriers versus controls, and 22q-dup carriers versus 22q-del carriers. All results described below are FDR-corrected unless otherwise indicated.

Sensitivity analyses. To determine whether group differences in brain structure are attributable to familial relationships between $22 \mathrm{q}$-dup patients, a sensitivity analysis was conducted on a subset of the duplication cohort comprising only unrelated individuals $(N=11)$, in which we determined whether the parameter estimates for this subset differed from those obtained on the full cohort. Specifically, we tested whether the adjusted means calculated for unrelated subjects were within 2 SEs of the adjusted means of the full cohort. 22q-dup patients in the subset were selected with the aim of maintaining similar mean age and sex ratios to the control and 22q-del group.

We conducted a similar secondary analysis to rule out the effect of antipsychotic medication on brain structure, in which 8 participants ( 7 22q-del carriers and 1 22q-dup carrier) who were taking antipsychotic medication at the time of visit were excluded. This approach was chosen as the small sample size of the subgroup precluded a mixed model analysis that explicitly accounted for family structure. Similarly, the confounding of medication use and group made a direct analysis of the effects of antipsychotic medication difficult to interpret. These sensitivity analyses are designed to show that the inclusion/exclusion of these participants does not bias the results.

Additionally, we conducted secondary analyses in which we covaried for: (1) race and (2) global brain metrics (mean cortical thickness and total cortical surface area).

\section{Results}

\section{Neuropsychiatric and cognitive findings}

There were significant differences in Full Scale IQ between groups: 22q-del carriers had the lowest IQ scores, followed by 22q-dup carriers, then control participants had the highest IQ scores (Table 1). The same pattern persisted for the Verbal IQ domain; however, for Nonverbal IQ (as measured by Matrix Reasoning), 22q-del carriers performed significantly more poorly than 22q-dup carriers and controls, who did not differ from each other. Four 22q-del carriers and no 22q-dup carriers were diagnosed with a psychotic disorder, but rates of ASD were elevated in both groups. 22q-del and 22q-dup carriers had similarly elevated scores on dimensional measures of autism-relevant symptomatology (Social Responsiveness Scale and Repetitive Behavioral Scale scales) relative to control participants.

\section{mRNA expression}

As shown in Figure 1, qRT-PCR analyses revealed a linear effect of gene dosage on mRNA expression levels of COMT and ZDHHC8, but not DGCR8 (Fig. 1).

\section{Gene dosage effects on global brain metrics}

There were no significant main effects of scanner location, but significant effects of group were found for total intracranial volume $\left(F_{(2,137)}=7.12, p=0.001\right)$, total gray matter volume $\left(F_{(2,136)}=\right.$ $5.43, p=0.005)$, cortical white matter volume $\left(F_{(2,136)}=11.88\right.$, $p=1.76 \mathrm{e}-5)$, total cortical SA $\left(F_{(2,137)}=35.37, p=4.1 \mathrm{e}-13\right)$, mean CT $\left(F_{(2,137)}=4.60, p=0.01\right)$, and the corpus callosum $\left(F_{(2,136)}=7.32, p=9.6 \mathrm{e}-4\right.$; Fig. $\left.2 A-F\right)$. Effects of gene dosage appeared generally proportional in magnitude relative to controls for callosal volume and cortical thickness, although for total intracranial, gray and white matter volume and SA, the percentage reduction in deletion carriers was more substantial than the relative increase seen in duplication carriers (Table 2; Fig. 2). Further, as shown in Figure 2, the effects of this CNV on brain structure did not appear to be accounted for by a subset of severely affected individuals, but rather, the entire distribution was shifted, suggesting a highly penetrant effect (Qureshi et al., 2014). Post hoc pairwise contrasts revealed that the significant effect of group was driven by patterns of differences between $22 \mathrm{q}$-del and 22q-dup carriers, as well as 22q-del carriers and controls.

\section{Effects of reciprocal 22q11.2 variation on cortical thickness}

Omnibus ANCOVA revealed a significant effect of group for 20 ROIs (Table 3). Across cortical regions, 22q-dup tended to show lower thickness compared with 22q-del with controls showing an intermediate pattern (Fig. 3). Post hoc pairwise $t$ tests revealed that, compared with controls, 22q-del showed significantly greater thickness in 8 ROIs and significantly lower thickness in 1 
Table 4. Regional SA adjusted means and SEs ${ }^{a}$

\begin{tabular}{|c|c|c|c|c|c|c|c|c|c|}
\hline Region & $F$ & $\begin{array}{l}\text { 22q-del, } \\
\text { mean (SE) }\end{array}$ & $\begin{array}{l}\text { Control, } \\
\text { mean (SE) }\end{array}$ & $\begin{array}{l}\text { 22q-dup, } \\
\text { mean (SE) }\end{array}$ & Region & $F$ & $\begin{array}{l}\text { 22q-del, } \\
\text { mean (SE) }\end{array}$ & $\begin{array}{l}\text { Control, } \\
\text { mean (SE) }\end{array}$ & $\begin{array}{l}\text { 22q-dup, } \\
\text { mean (SE) }\end{array}$ \\
\hline Left hemisphere & & & & & Righthemisphere & & & & \\
\hline Bank of superior temporal sulcus**,,,$+\dagger$ & 16.1 & $941.0(19.9)$ & $1049.5(21.7)$ & $1169.4(38.3)$ & Bank of superior temporal sulcus** $, t,+\dagger$ & 24.6 & $882.7(16.2)$ & $1031.1(17.6)$ & $1062.8(31.2)$ \\
\hline Caudal middle frontal gyrus & 4.5 & $2172.4(47.1)$ & $2342.8(51.3)$ & $2422.2(90.7)$ & Caudal middle frontal gyrus & 3.4 & $1936.7(49.6)$ & $2103.6(54.1)$ & $2143.2(95.6)$ \\
\hline Cuneus $^{* *}, t,+\dagger$ & 59.7 & $1139.3(23.8)$ & $1479.2(25.9)$ & $1550.7(45.8)$ & Cuneus ${ }^{* *}, t, t \dagger$ & 43.6 & $1213.9(24.5)$ & $1522.3(26.6)$ & $1553.4(47.1)$ \\
\hline Entorhinal cortex* ${ }^{* *}, \dagger$ & 6.2 & $340.5(10)$ & $369.6(10.9)$ & $414.1(19.2)$ & Entorhinal cortex & 5.1 & $288.0(8.8)$ & $326.8(9.6)$ & $328.0(17)$ \\
\hline Inferior parietal cortex & 5.5 & $4415.6(70.2)$ & $4758.8(76.5)$ & $4621.3(135.3)$ & Inferior parietal cortex ${ }^{* *}, \dagger,+\dagger$ & 13.1 & $5129.4(86)$ & $5715.1(93.7)$ & $5808.7(165.6)$ \\
\hline Inferior temporal gyrus ${ }^{* *}, \dagger,+\dagger$ & 32.0 & $2832.7(50.7)$ & $3402.2(55.3)$ & $3371.4(97.7)$ & Inferior temporal gyrus ${ }^{* *}, \uparrow, \uparrow \dagger$ & 19.0 & $2746.9(57)$ & $3237.9(62.1)$ & $3223.3(109.9)$ \\
\hline Insula & 2.5 & $2020.5(28.2)$ & $2056.6(30.7)$ & $2156.5(54.2)$ & Insula & 0.7 & $2070.9(32.7)$ & $2032.4(35.6)$ & $2112.2(63)$ \\
\hline Isthmus cingulate ${ }^{* *}, \mathrm{t} \dagger$ & 8.8 & $960.2(19.9)$ & $1012.1(21.7)$ & $1140.5(38.3)$ & Isthmus cingulate & 4.4 & $904.4(19.5)$ & $920.9(21.3)$ & $1030.1(37.7)$ \\
\hline Lateral occipital cortex ${ }^{* *}, \dagger,+\dagger$ & 21.5 & $4315.6(67)$ & $4851.8(73)$ & $5082.6(129.1)$ & Lateral occipital cortext, $+\dagger$ & 13.5 & $4155.7(76.2)$ & $4708.4(83)$ & $4688.1(146.8)$ \\
\hline Lateral orbitofrontal cortex & 4.2 & $2403.1(38.2)$ & $2551.7(41.6)$ & $2571.2(73.6)$ & Lateral orbitofrontal cortex & 3.2 & $2310.9(40.6)$ & $2444.1(44.2)$ & $2475.3(78.2)$ \\
\hline Parahippocampal gyrus & 4.6 & $696.3(14.6)$ & $730.4(15.9)$ & $790.9(28.2)$ & Parahippocampal gyrus ${ }^{* *}, \mathrm{t \dagger}$ & 7.3 & $633.2(11)$ & $683.1(12)$ & $708.9(21.3)$ \\
\hline Pars opercularis & 1.8 & $1634.4(32.7)$ & $1715.0(35.6)$ & $1731.9(63)$ & Pars opercularis & 0.3 & $1348.7(27.7)$ & $1381.2(30.2)$ & $1367.4(53.3)$ \\
\hline Pars orbitalis & 1.7 & $602.8(10.6)$ & $623.3(11.5)$ & $641.1(20.4)$ & Pars orbitalis & 3.4 & $731.5(12.7)$ & $777.0(13.8)$ & $777.3(24.4)$ \\
\hline Pars triangularis ${ }^{* *}, \dagger, \dagger \dagger$ & 10.0 & $1201.2(25.3)$ & $1345.2(27.5)$ & $1388.8(48.7)$ & Pars triangularis**,,,$+\dagger$ & 15.5 & $1328.8(28.4)$ & $1536.1(30.9)$ & $1578.3(54.7)$ \\
\hline Pericalcarine gyrus $s^{* *}, \uparrow, \uparrow \dagger$ & 35.5 & $1070.8(25.7)$ & $1361.9(28)$ & $1398.2(49.6)$ & Pericalcarine gyrus ${ }^{* *}, \mathrm{t}, \dagger$ & 38.4 & $1193.6(26.1)$ & $1514.1(28.4)$ & $1499.0(50.3)$ \\
\hline Postcentral gyrus ${ }^{* *}, \mathrm{,}, \dagger$ & 17.4 & $3819.5(55.9)$ & $4260.0(61)$ & $4323.3(107.8)$ & Postcentral gyrus**,,,$+ \dagger$ & 28.8 & $3576.2(58.4)$ & $4170.3(63.7)$ & $4247.1(112.6)$ \\
\hline Posterior cingulate ${ }^{* *}, \uparrow, \uparrow \dagger$ & 14.0 & $1108.8(21.1)$ & $1226.8(23)$ & $1326.2(40.7)$ & Posteriorcingulate gyrus ${ }^{* *}, \mathrm{t}, \dagger$ & 14.1 & $1093.6(23.7)$ & $1256.2(25.8)$ & $1297.5(45.6)$ \\
\hline Precentral gyrus & 1.3 & $4737.2(63.4)$ & $4795.0(69.1)$ & $4960.8(122.1)$ & Precentral gyrus & 1.4 & $4722.6(63.7)$ & $4878.9(69.4)$ & $4820.4(122.8)$ \\
\hline Precuneus** $, t, \dagger \dagger$ & 36.3 & $3296.2(53.3)$ & $3893.8(58.1)$ & $4009.7(102.7)$ & Precuneus ${ }^{* *}, t, \dagger \dagger$ & 30.6 & $3427.1(60.4)$ & $3990.3(65.8)$ & $4273.1(116.4)$ \\
\hline Rostral anterior cingulate ${ }^{* *}, \mathrm{t}, \mathrm{t}$ & 33.7 & $641.6(19)$ & $807.5(20.6)$ & $942.8(36.5)$ & Rostral anterior cingulate gyrus ${ }^{* *}, \mathrm{t}, \mathrm{t}$ & 15.7 & $580.8(16.1)$ & $670.0(17.5)$ & $761.4(31)$ \\
\hline Rostral middle frontal gyrus**, $, \mathrm{t}, \mathrm{t}$ & 26.3 & $4919.1(88.9)$ & $5784.2(96.8)$ & $5892.9(171.2)$ & Rostral middle frontal gyrus**,,,$+\dagger$ & 34.6 & $5009.6(88.6)$ & $6005.9(96.5)$ & $6101.4(170.6)$ \\
\hline Superior frontal cortex ${ }^{* *}, t, \dagger \dagger$ & 15.2 & $6670.0(95.9)$ & $7369.3(104.5)$ & $7495.3(184.9)$ & Superior frontal gyrus** $, \mathrm{t}, \mathrm{\dagger}$ & 11.4 & $6533.1(98.5)$ & $7113.8(107.4)$ & $7344.0(189.9)$ \\
\hline
\end{tabular}

${ }^{a}$ Adjusted means are covaried for age, sex, and scanner location.

**Survives FDR correction ( $p<0.05$ threshold) at post hoc level for 22q-dup versus 22q-del.

†Survives FDR correction ( $p<0.05$ threshold) at post hoc level for 22q-del versus control.

t+Survives FDR correction ( $p<0.05$ threshold) at omnibus level.

ROI. In contrast, 22q-dup carriers had significantly lower CT relative to controls, specifically in 3 lateral frontal and parietal ROIs: the left caudal and superior frontal gyrus, and the right precuneus (Table 3). 22q-dup carriers also showed cortical thinning relative to controls at a nominal uncorrected $p<0.05$ level in predominantly frontal and sensorimotor regions (Fig. 4A). As shown in Figure 3, the decreases in 22q-dup carriers in regional cortical thickness measures are proportional to the increases observed in 22q-del carriers, albeit in somewhat different cortical regions; specifically, increased CT in 22q-del carriers was greatest in the insula and inferior frontal regions, whereas reductions of $\mathrm{CT}$ in 22q-dup were greatest in frontoparietal regions.

\section{Opposing effects on cortical surface area}

Pervasive effects of gene dosage were observed for cortical SA with significant effects of group for 52 ROIs (Table 4). Cortical SA showed a pattern opposite to that observed for CT: 22q-dup carriers largely showed greater SA compared with 22q-del carriers and controls mostly intermediate (Fig. 5). No differences between 22q-dup and controls survived correction, but 16 ROIs showed nominally significant differences at an uncorrected $p<$ 0.05 level (Fig. 4B). These regions included most of the cortex with differences of greatest magnitude observed in medial frontal cortex, the cingulate, superior temporal gyrus, and bank of the superior temporal sulcus (Fig. 5), notably, key components of social cognitive neural circuitry (Lieberman, 2007).

Moreover, there was a notable divergence in the brain regions predominantly affected by the deletion versus duplication. Although reductions of cortical SA were of greatest magnitude in parietal regions for 22q-del carriers, SA increases in the duplication group were greatest in frontotemporal and midline regions (i.e., cingulate cortex).

Effect size plots for 22q-dup carriers versus controls confirmed a global divergent pattern between CT and SA: SA was larger in 22qdup carriers relative to controls (median effect size: Cohen's $d=$ -0.22 ) with a negative value indicating larger cortical SA in 22q-dup carriers (Fig. 6B). Effects on CT, although more localized, were generally in the opposite direction. 22q-dup carriers showed lower thickness relative to controls (median effect size: Cohen's $d=0.20$ ), most notably in superior frontal regions (Fig. 6A).

\section{Post hoc power analysis for regional cortical thickness and surface area}

Maps of post hoc power calculations, estimating the sample size needed to achieve a significant group difference in 22q-dup car- 


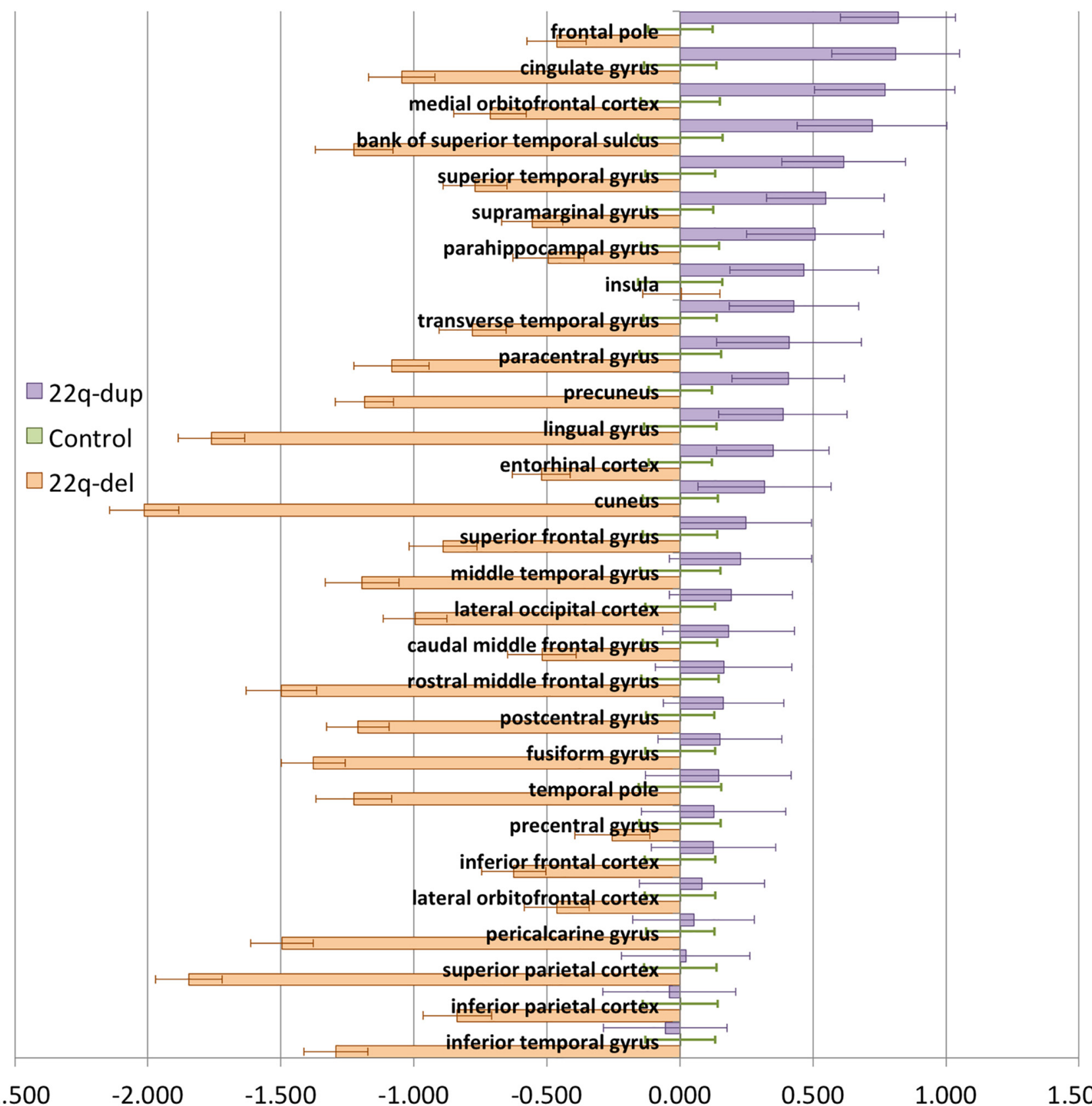

Figure 5. Cortical surface area. zscore plots of estimated marginal mean \pm SE. zscores are derived from individual subject means adjusted for sex, age, and scanner location using control mean and SD for each region. Then, $z$ scores were submitted to the same primary statistical analysis to generate estimated marginal mean \pm SE. 22q-dup showed greater surface area relative to $22 q$-del patients in predominantly medial frontal and superior temporal regions, with controls showing an intermediate pattern.

riers versus controls across cortical regions (Fig. 6C,D), indicate that there is substantial regional variability in the effects of the 22q11.2 duplication on brain structure. With a sample size approximately equivalent to that of our deletion and control groups, we would also be likely to find significant thickness differences in additional frontoparietal regions in the duplication cohort (i.e., the bilateral supramarginal, precentral and postcentral gyrus, and left entorhinal cortex and insula). However, much larger samples would be required to observe thickness differences in temporal structures, as indicated by the smaller effect sizes in these regions. The regional distribution of effect sizes differs somewhat for cortical SA (Fig. 6D). With comparable sample sizes to our deletion and control groups, we would likely identify significant differences in SA in midline and right lateral parietal regions, as well as the frontal pole and left temporal regions (entorhinal cortex, bank of the superior temporal sulcus) in duplication carriers versus controls. However, in other regions, the effects were quite small, likely requiring several hundred subjects to detect a significant group difference.

Patterns extend to subcortical structures: volume and morphometry

Significant effects of group extended into subcortical structures. Although pairwise differences between 22q-dup carriers and controls did not survive multiple comparisons correction for global subcortical volumes or local shape metrics, there were significant differences between 22q-dup and 22q-del carriers. Pairwise significant differences, indicating lower volume in 22q-del carriers com- 


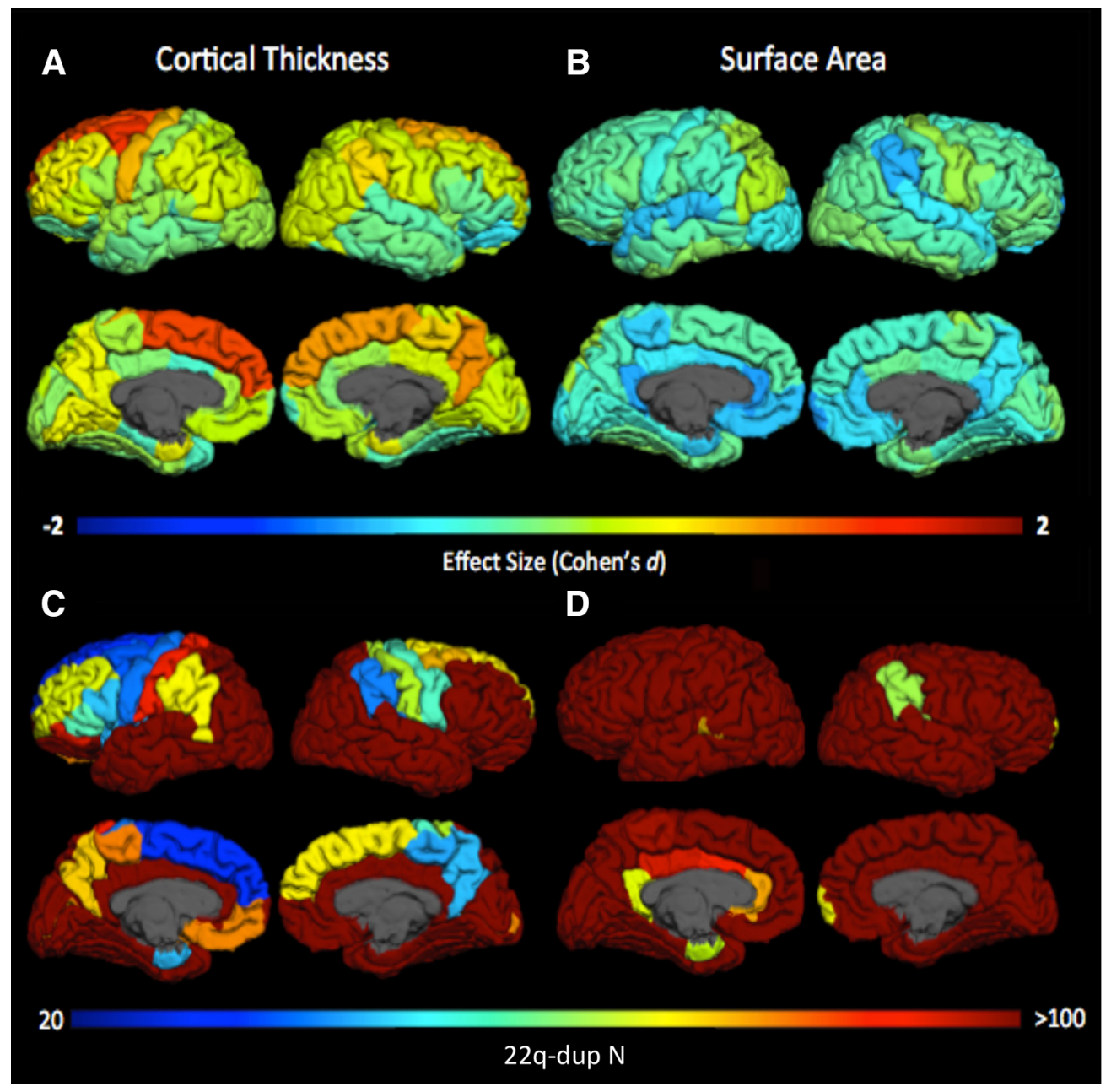

Figure 6. Effect size maps for 22q-dup carriers versus controls. $A, B$, Cohen's $d$ is displayed for each ROI adjusted for age, sex, and scanner for 22q-dup carriers and controls. Cooler colors represent regions in which 22q-dup carriers show greater thickness or area. Warmer colors represent regions in which controls show greater thickness or area. For thickness, effect sizes ranged from -0.5 to 1.4 (median: 0.2), with controls showing greater thickness particularly in medial frontal regions. 22q-dup carriers showed widespread increases in surface area relative to controls, across multiple cortical regions (median effect size: -0.22 ; range -0.82 to 0.24 ). C, $\boldsymbol{D}$, Estimated number of 22q-dup carriers needed to achieve a statistically significant difference from controls with $80 \%$ power, for each ROI. Raw values (not adjusted for any covariates) and Bonferroni correction for the number of regions were used to reduce model assumptions, resulting in conservative estimates.

Table 5. Subcortical volume: adjusted means, SEs, and estimated 22q-dupN ${ }^{a}$

\begin{tabular}{|c|c|c|c|c|c|c|c|c|c|c|c|}
\hline Region & $F$ & $\begin{array}{l}\text { 22q-del, } \\
\text { mean (SE) }\end{array}$ & $\begin{array}{l}\text { Control, } \\
\text { mean (SE) }\end{array}$ & $\begin{array}{l}\text { 22q-dup, } \\
\text { mean (SE) }\end{array}$ & $\operatorname{dupN}$ & Region & $F$ & $\begin{array}{l}\text { 22q-del, } \\
\text { mean (SE) }\end{array}$ & $\begin{array}{l}\text { Control, } \\
\text { mean (SE) }\end{array}$ & $\begin{array}{l}\text { 22q-dup, } \\
\text { mean (SE) }\end{array}$ & dupN \\
\hline Left hemisp & & & & & & Right & & & & & \\
\hline Accumbens & 2.7 & $852.7(15.0)$ & $803.6(15.9)$ & $807.2(28.0)$ & $>1000$ & Accumbens & 5.8 & $815.7(13.1)$ & $749.6(13.9)$ & $774.3(24.5)$ & $>1000$ \\
\hline Caudate & 4.9 & $4058.0(54.2)$ & $3872.5(57.5)$ & $3729.0(101.2)$ & 363 & Caudate ${ }^{* *}, \mathrm{t}, \mathrm{t \dagger}$ & 10.5 & $4423.3(55.8)$ & $4091.8(59.3)$ & $3997.7(104.4)$ & 435 \\
\hline Hippocampust, & 8.6 & $3790.8(56.3)$ & $4132.8(59.8)$ & $4054.5(105.3)$ & $>1000$ & npus ${ }^{* *}, \dagger, \dagger \dagger$ & 8.2 & $3789.8(53.9)$ & $4074.8(57.2)$ & $4147.3(100.7)$ & 155 \\
\hline Inferior lateral ventricle ${ }^{* *}, t,{ }^{\prime}+$ & 17.6 & $505.4(26.2)$ & $295.9(27.8)$ & $263.8(48.9)$ & $>1000$ & Inferior lateral ventricle ${ }^{* *}, \mathrm{t}, \mathrm{t}$ & 19.0 & $483.9(27.7)$ & $239.1(29.4)$ & $265.1(51.7)$ & 4 \\
\hline Lateral ventriclet, & 9.4 & $8339.6(510.4)$ & $5042.0(541.6)$ & $6534.2(953.9)$ & 189 & Lateral ventriclet, $+\dagger$ & 15.0 & $7967.4(475.7)$ & $4094.3(504.7)$ & $6062.3(888.9)$ & 80 \\
\hline allidum & 0.4 & $1787.5(35.4)$ & $1834.2(37.5)$ & $1817.2(66.1)$ & $>1000$ & Pallidum & 0.4 & $(25.0)$ & $1670.5(26.5)$ & $1704.9(46.6)$ & $>1000$ \\
\hline utamen & 1.0 & $6468.2(87.2)$ & $6558.3(92.5)$ & $6302.9(162.9)$ & 465 & Putamen & 1.6 & $6053.1(75.0)$ & $6247.9(79.5)$ & $6092.9(140.1)$ & 384 \\
\hline halamus & 1.3 & 7269.6 (75.4) & $7421.2(80.0)$ & $7484.6(141.0)$ & 658 & Thalamus & 1.8 & 7325.2 (73.2) & 7295.5 (77.7) & 7033.2 (136.8) & 892 \\
\hline
\end{tabular}

${ }^{a}$ Adjusted means are covaried for age, sex, scanner location, and intracranial volume.

**Survives FDR correction ( $p<0.05$ threshold) at post hoc level for 22q-dup versus 22q-del.

tSurvives FDR correction ( $p<0.05$ threshold) at post hoc level for 22q-del versus control.

ttSurvives FDR correction ( $p<0.05$ threshold) at omnibus level.

pared with 22q-dup carriers, were found for the right hippocampus (Table 5). In contrast, the right caudate displayed an opposite pattern: 22q-del carriers showed greater volume, whereas 22q-dup showed a decrease in volume compared with controls.

Novel shape analysis methods revealed a widespread and complex pattern of differences in local thickness measures between 22q-del and 22q-dup carriers in subcortical regions (Fig. 7). Compared with $22 \mathrm{q}$-del carriers, $22 \mathrm{q}$-dup carriers had predominantly greater local thickness in bilateral hippocampal, left thalamus, and right amygdala structures. However, some smaller subregions of the hippocampi showed the opposite effect. Based on prior surface-based mapping of hippocampal subfields (Mamah 


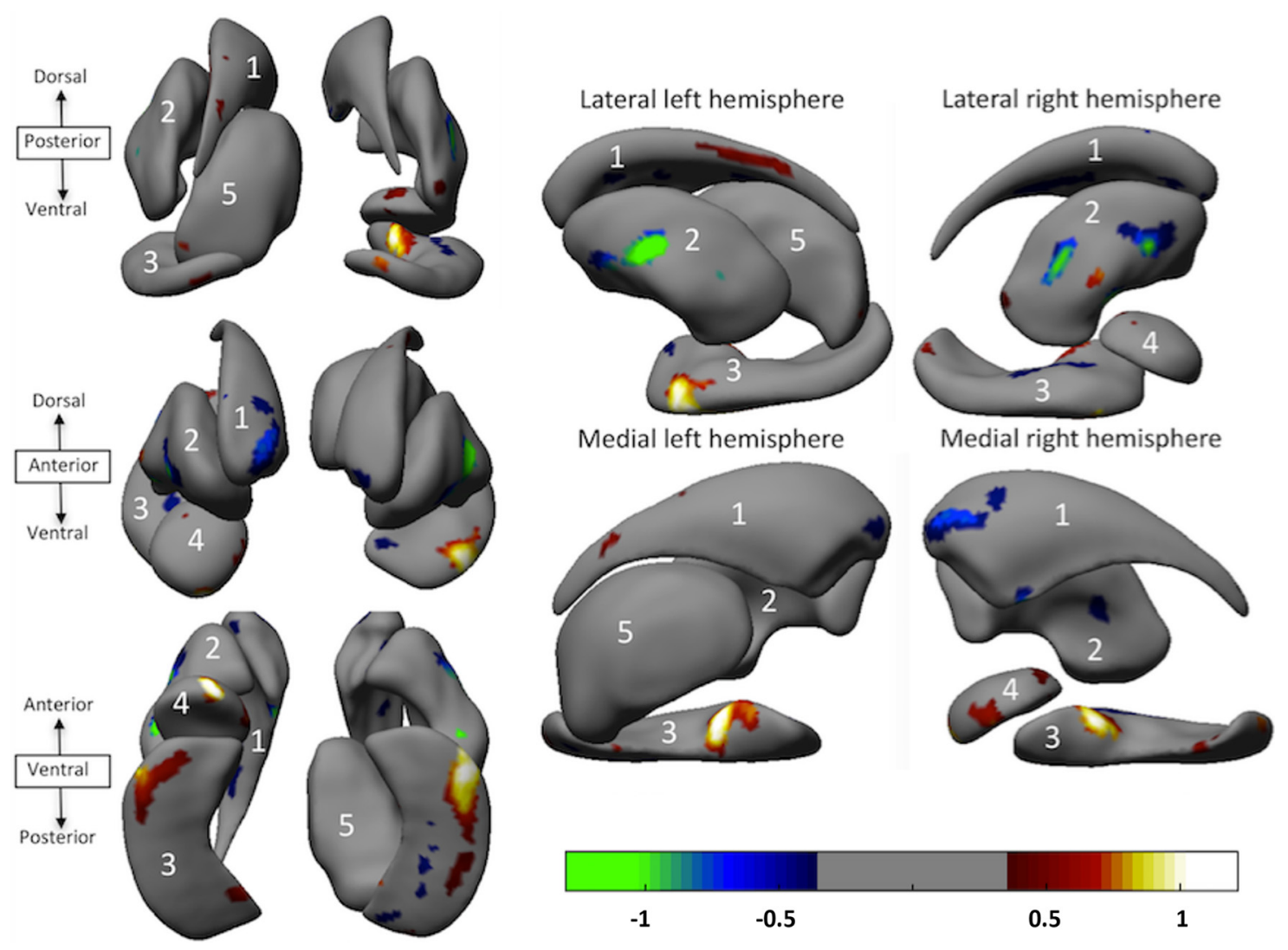

Figure 7. Subcortical shape differences. Radial distance maps for $22 q-d u p$ versus $22 q-d e l$ carriers, showing $\beta$ values, adjusted for sex, age, scanner, and intracranial volume, for regions passing correction for multiple comparisons at $q<0.05$. Cooler colors represent negative $\beta$ values (regions of lower local thickness or volume in 22q-dup vs 22q-del). Warmer colors represent positive $\beta$ values (regions of greater local thickness or volume in 22q-dup vs 22q-del). Only structures that showed differences between 22q-dup and 22q-del that survive correction are displayed, as no significant differences were found between 22q-dup and controls. 1, Caudate; 2, putamen; 3, hippocampus; 4, amygdala; 5, thalamus.

et al., 2016), regions of greater thickness in the 22q-dup carriers approximately correspond to subiculum and CA1 regions, whereas decreased thickness in 22q-dup carriers approximately corresponds to CA2-4/dentate subfield regions. In contrast, largely lower local thickness measures were found in bilateral putamen and caudate structures in 22q-dup relative to 22q-del carriers with small localized regions of greater thickness.

\section{Sensitivity analyses}

Sensitivity analyses revealed that neither familial relatedness nor antipsychotic medication generally influenced the parameter estimates of interest. For the subsample of unrelated individuals, the estimated effects for all global metrics, as well as the ROIs showing significant 22q-dup versus control differences, were all within 2 SEs of the estimated effects in the primary analyses (Table 6). Similarly, the results of the analyses excluding participants on antipsychotics were within 2 SEs of the estimates obtained in the primary analyses for all ROIs.

Moreover, covarying for race did not alter our overall pattern of findings. Specifically, significant $22 \mathrm{q}$-dup versus control differences in cortical thickness in all previously identified ROIs (the left caudal and superior frontal gyrus, and the right precuneus) remained significant, and an additional region, the right superior frontal gyrus, was also found to be significantly different.

Finally, after adjusting for mean thickness (Table 7), 7 of the 17 ROIs remained significant for 22q-del versus 22q-dup differences. The 3 ROIs in which we observed 22q-dup versus control differences remained significant, regardless of whether average
Table 6. Full dataset versus unrelated 22q-dup patients: adjusted means and SEs

\begin{tabular}{lccl}
\hline Measure & $\begin{array}{c}\text { Full dataset 22q-dup } \\
\text { adjusted, mean (SE) }\end{array}$ & $\begin{array}{c}\text { Unrelated 22q-dup } \\
\text { adjusted, mean (SE) }\end{array}$ & $\begin{array}{l}\text { Within } \\
\text { 2SEs? }\end{array}$ \\
\hline Corpus callosum volume & $2723.9(113.5)$ & $2737.4(149.7)$ & Yes \\
Cortical white matter volume & $415,362.7(6319.3)$ & $411,210.5(8372.5)$ & Yes \\
Total gray matter & $581,072.5(8947.3)$ & $5738,25.4(11956.8)$ & Yes \\
Mean thickness & $2.71(0.02)$ & $2.70(0.03)$ & Yes \\
Total intracranial volume & $1,466,356.0(27086.6)$ & $1,466,689.9(35730.6)$ & Yes \\
Total area & $176,466.1(3390.9)$ & $174,713.5(4522.6)$ & Yes \\
Left caudal middle frontal gyrus & $2.58(0.04)$ & $2.56(0.05)$ & Yes \\
Left superior frontal gyrus & $2.84(0.04)$ & $2.83(0.05)$ & Yes \\
Right precuneus & $2.50(0.04)$ & $2.49(0.05)$ & Yes \\
\hline
\end{tabular}

cortical thickness was included as a covariate or not, indicating localized effects of the 22q11.2 CNV on thickness. In contrast, covarying for total SA reduced the magnitude of deletionduplication differences in regional SA measures. Specifically, only 8 of the 50 previously identified ROIs remained significantly different for $22 \mathrm{q}$-del versus $22 \mathrm{q}$-dup comparisons (Table 8), suggesting that our SA results should be interpreted as a diffuse, global surface deficit in 22q11.2 deletion carriers with additional regional accentuation in occipitoparietal and cingulate regions.

\section{Discussion}

22q11.2 copy number variation was associated with global opposing effects on brain structure, involving widespread cortical SA reductions in deletion carriers with corresponding enlargement in duplication carriers. CT showed an opposite, more lo- 
Table 7. Regional cortical thickness: adjusted means and SEs with additional mean thickness covariate ${ }^{a}$

\begin{tabular}{|c|c|c|c|c|c|c|c|c|c|}
\hline Region & $F$ & $\begin{array}{l}\text { 22q-del, } \\
\text { mean (SE) }\end{array}$ & $\begin{array}{l}\text { Control, } \\
\text { mean (SE) }\end{array}$ & $\begin{array}{l}\text { 22q-dup, } \\
\text { mean (SE) }\end{array}$ & Region & $F$ & $\begin{array}{l}\text { 22q-del, } \\
\text { mean (SE) }\end{array}$ & $\begin{array}{l}\text { Control, } \\
\text { mean (SE) }\end{array}$ & $\begin{array}{l}\text { 22q-dup, } \\
\text { mean (SE) }\end{array}$ \\
\hline Left hemisphere & & & & & Right hemisphere & & & & \\
\hline Bank of superior temporal sulcus ${ }^{* *},{ }^{*}$ & 9.3 & $2.63(0.02)$ & $2.72(0.02)$ & $2.8(0.04)$ & Bank of superior temporal sulcus & 4.9 & $2.81(0.02)$ & $2.87(0.02)$ & $2.94(0.04)$ \\
\hline Caudal anterior cingulate gyrus ${ }^{* *},{ }^{+}$ & 9.1 & $2.81(0.03)$ & $2.97(0.04)$ & $3.08(0.06)$ & Caudal anterior cingulate gyrus & 6.4 & $2.68(0.03)$ & $2.84(0.03)$ & $2.84(0.06)$ \\
\hline Caudal middle frontal gyrus $, * *,+†, \ddagger$ & 14.4 & $2.8(0.01)$ & $2.76(0.02)$ & $2.63(0.03)$ & Caudal middle frontal gyrus ${ }^{* *}, \mathrm{t}, \ddagger$ & 7.7 & $2.73(0.02)$ & $2.68(0.02)$ & $2.6(0.03)$ \\
\hline Cuneus & 1.0 & $2.11(0.02)$ & $2.07(0.02)$ & $2.09(0.04)$ & Cuneus & 0.8 & $2.15(0.02)$ & $2.12(0.02)$ & $2.1(0.04)$ \\
\hline Entorhinal cortex & 1.9 & $3.46(0.04)$ & $3.57(0.05)$ & $3.44(0.08)$ & Entorhinal cortex & 0.8 & $3.78(0.05)$ & $3.82(0.05)$ & $3.69(0.09)$ \\
\hline Frontal pole & 2.3 & $2.81(0.04)$ & $2.92(0.04)$ & $2.96(0.08)$ & Frontal pole & 1.1 & $2.8(0.04)$ & $2.78(0.04)$ & $2.92(0.08)$ \\
\hline Fusiform gyrus & 1.1 & $2.89(0.01)$ & $2.91(0.02)$ & $2.93(0.03)$ & Fusiform gyrus & 1.9 & $2.99(0.01)$ & $2.97(0.01)$ & $3.03(0.03)$ \\
\hline Inferior parietal cortex & 0.9 & $2.69(0.01)$ & $2.71(0.01)$ & $2.69(0.02)$ & Inferior parietal cortex & 0.4 & $2.72(0.01)$ & $2.71(0.01)$ & $2.69(0.02)$ \\
\hline Inferior temporal gyrus & 1.7 & $2.86(0.02)$ & $2.9(0.02)$ & $2.94(0.04)$ & Inferior temporal gyrus & 1.4 & $3.03(0.02)$ & $3.03(0.02)$ & $3.09(0.03)$ \\
\hline Insula ${ }^{* *}, t, \dagger+, \ddagger$ & 18.6 & $3.4(0.02)$ & $3.26(0.02)$ & $3.26(0.03)$ & Insula & 3.9 & $3.4(0.02)$ & $3.32(0.02)$ & $3.35(0.04)$ \\
\hline Isthmus cingulate & 0.7 & $2.77(0.03)$ & $2.78(0.03)$ & $2.71(0.05)$ & Isthmus cingulate & 1.5 & $2.64(0.02)$ & $2.69(0.02)$ & $2.66(0.04)$ \\
\hline Lateral occipital cortex & 0.2 & $2.33(0.01)$ & $2.34(0.02)$ & $2.35(0.03)$ & Lateral occipital cortex & 0.6 & $2.4(0.02)$ & $2.43(0.02)$ & $2.4(0.03)$ \\
\hline Lateral orbitofrontal cortex & 2.1 & $2.89(0.02)$ & $2.86(0.02)$ & $2.93(0.03)$ & Lateral orbitofrontal cortex & 6.2 & $2.73(0.02)$ & $2.73(0.02)$ & $2.86(0.04)$ \\
\hline Lingual gyrus & 5.3 & $2.29(0.02)$ & $2.24(0.02)$ & $2.2(0.03)$ & Lingual gyrus & 4.0 & $2.37(0.02)$ & $2.31(0.02)$ & $2.29(0.03)$ \\
\hline Medial orbitofrontal cortex & 3.2 & $2.67(0.03)$ & $2.59(0.03)$ & $2.57(0.05)$ & Medial orbitofrontal cortex & 2.3 & $2.52(0.02)$ & $2.46(0.02)$ & $2.45(0.04)$ \\
\hline Middle temporal gyrus & 0.8 & $3.03(0.02)$ & $3.03(0.02)$ & $3.08(0.04)$ & Middle temporal gyrus & 0.9 & $3.12(0.02)$ & $3.1(0.02)$ & $3.15(0.04)$ \\
\hline Paracentral gyrus & 3.9 & $2.65(0.02)$ & $2.57(0.02)$ & $2.58(0.04)$ & Paracentral gyrus & 4.8 & $2.68(0.02)$ & $2.64(0.02)$ & $2.55(0.04)$ \\
\hline Parahippocampal gyrus ${ }^{* *}, \dagger, \dagger \dagger, \ddagger$ & 17.5 & $2.68(0.04)$ & $2.95(0.04)$ & $3.06(0.07)$ & Parahippocampal gyrus & 2.0 & $2.93(0.04)$ & $3.02(0.04)$ & $3.04(0.07)$ \\
\hline Pars opercularist, $\dagger+, \ddagger$ & 11.4 & $2.87(0.01)$ & $2.78(0.01)$ & $2.8(0.02)$ & Pars opercularis & 1.1 & $2.79(0.02)$ & $2.76(0.02)$ & $2.8(0.04)$ \\
\hline Pars orbitalis & 2.0 & $2.98(0.03)$ & $2.93(0.03)$ & $2.88(0.05)$ & Pars orbitalis & 1.4 & $2.8(0.03)$ & $2.75(0.03)$ & $2.86(0.06)$ \\
\hline Pars triangularis $\dagger, \mathrm{\dagger}, \neq$ & 9.6 & $2.74(0.02)$ & $2.63(0.02)$ & $2.63(0.03)$ & Pars triangularis & 1.2 & $2.61(0.03)$ & $2.56(0.03)$ & $2.62(0.05)$ \\
\hline Pericalcarine gyrus & 2.6 & $1.84(0.02)$ & $1.79(0.02)$ & $1.75(0.04)$ & Pericalcarine gyrus & 6.5 & $1.86(0.02)$ & $1.76(0.02)$ & $1.74(0.04)$ \\
\hline Postcentral gyrus & 3.0 & $2.26(0.02)$ & $2.21(0.02)$ & $2.23(0.03)$ & Postcentral gyrus & 1.6 & $2.26(0.02)$ & $2.22(0.02)$ & $2.19(0.04)$ \\
\hline Posterior cingulate & 0.8 & $2.78(0.02)$ & $2.81(0.02)$ & $2.82(0.04)$ & Posterior cingulate & 3.9 & $2.71(0.02)$ & $2.79(0.02)$ & $2.75(0.04)$ \\
\hline Precentral gyrus & 5.3 & $2.74(0.01)$ & $2.72(0.01)$ & $2.65(0.02)$ & Precentral gyrus & 2.0 & $2.71(0.02)$ & $2.67(0.02)$ & $2.65(0.03)$ \\
\hline Precuneus & 1.3 & $2.65(0.01)$ & $2.65(0.01)$ & $2.61(0.02)$ & Precuneus*,**, $,+\uparrow, \ddagger$ & 8.5 & $2.68(0.02)$ & $2.68(0.02)$ & $2.56(0.03)$ \\
\hline Rostral anterior cingulate & 0.2 & $3.15(0.03)$ & $3.17(0.03)$ & $3.18(0.06)$ & Rostral anterior cingulate & 6.2 & $2.81(0.03)$ & $2.94(0.03)$ & $2.98(0.06)$ \\
\hline Rostral middle frontal gyrus & 5.3 & $2.62(0.02)$ & $2.56(0.02)$ & $2.53(0.03)$ & Rostral middle frontal gyrus & 4.6 & $2.44(0.02)$ & $2.37(0.02)$ & $2.36(0.03)$ \\
\hline Superior frontal cortex ${ }^{*},{ }^{* *}, \mathrm{t \dagger}, \ddagger$ & 12.1 & $3.03(0.01)$ & $3.02(0.01)$ & $2.89(0.03)$ & Superior frontal cortex & 6.3 & $2.91(0.01)$ & $2.9(0.02)$ & $2.8(0.03)$ \\
\hline Superior parietal cortex & 0.1 & $2.39(0.02)$ & $2.39(0.02)$ & $2.38(0.03)$ & Superior parietal cortex & 0.3 & $2.38(0.02)$ & $2.36(0.02)$ & $2.35(0.03)$ \\
\hline Superior temporal gyrust, $+\uparrow, \ddagger$ & 23.0 & $2.87(0.02)$ & $3.01(0.02)$ & $3.03(0.03)$ & Superior temporal gyrus & 4.2 & $2.97(0.02)$ & $3.01(0.02)$ & $3.08(0.03)$ \\
\hline Supramarginal gyrus & 4.1 & $2.84(0.01)$ & $2.79(0.02)$ & $2.76(0.03)$ & Supramarginal gyrus**, & 11.1 & $2.87(0.01)$ & $2.81(0.01)$ & $2.76(0.02)$ \\
\hline Temporal pole & 1.1 & $3.67(0.04)$ & $3.69(0.05)$ & $3.8(0.08)$ & Temporal pole & 0.1 & $3.9(0.04)$ & $3.92(0.05)$ & $3.89(0.08)$ \\
\hline Transverse temporal gyrus & 2.8 & $2.55(0.03)$ & $2.64(0.03)$ & $2.63(0.05)$ & Transverse temporal gyrus & 1.9 & $2.66(0.03)$ & $2.62(0.03)$ & $2.73(0.05)$ \\
\hline
\end{tabular}

${ }^{a}$ Adjusted means are covaried for age, sex, scanner location, and mean thickness.

**Survives FDR correction ( $p<0.05$ threshold) at post hoc level for 22q-dup versus 22q-del.

†Survives FDR correction ( $p<0.05$ threshold) at post hoc level for 22q-del versus control.

t†Survives FDR correction ( $p<0.05$ threshold) at omnibus level.

\#FDR-corrected omnibus effect as well as FDR-corrected del-dup or dup-con difference that remain significant with inclusion of mean thickness covariate.

calized pattern. These findings were not accounted for by a subset of individuals, but rather the entire distribution was shifted, suggesting a highly penetrant effect of gene dosage.

\section{2q11.2 gene dosage implications for neuropsychiatric disorders}

There is now replicated evidence that duplications at $22 \mathrm{q} 11.2$ are substantially less common in schizophrenia cases than in the general population, but reciprocal deletions are an established strong risk factor for schizophrenia (Rees et al., 2014, 2016). Our findings suggest a possible underlying neurobiological basis for these divergent behavioral phenotypes. We found opposing effects of CT and SA in in 22q-del versus 22q-dup in medial temporal and frontal brain regions strongly implicated in idiopathic schizophrenia (Palaniyappan et al., 2011; Shepherd et al., 2012), suggesting relevant underlying brain mechanisms that may be selective for schizophrenia. Alternatively, because both $22 \mathrm{q}-$ del and 22q-dup confer increased risk for ASD, opposing effects in common brain regions implicated in autism (Ecker et al., 2013; Wallace et al., 2015; Ohta et al., 2016) (e.g., decreased vs increased SA in medial frontal regions in $22 \mathrm{q}-\mathrm{del}$ and $22 \mathrm{q}-$ dup, respectively) may result in similar downstream phenotypic effects on traits, such as language delay and reciprocal social behavior deficits. Future, prospective longitudinal brain-behavior investigations in these two groups are necessary to test these hypotheses.

\section{2q11.2 gene dosage effects on brain structure}

Critical to our study framework, we separately measured CT and SA, two cortical measures that likely have different phylogenetic and ontogenetic origins (Rakic, 1995; Panizzon et al., 2009) and distinct developmental trajectories (Raznahan et al., 2011; Wierenga et al., 2014). Our findings of opposing directions of effect, as well as more pervasive effects of the $22 \mathrm{q} 1 \mathrm{CNV}$ on SA relative to $\mathrm{CT}$, suggest that different mechanisms may be involved. In particular, increased progenitor cell production during early embryonic development predominantly influences SA expansion (Rakic, 1988); thus, widespread SA decreases in 22q-del may reflect reduced production of progenitor cells in multiple cortical areas, implying that these divergent phenotypes arise early in the course of development. Nevertheless, these effects were not entirely proportional in magnitude, as deletions conferred a rela- 
Table 8. Regional SA: adjusted means and SEs with additional total area covariate ${ }^{a}$

\begin{tabular}{|c|c|c|c|c|c|c|c|c|c|}
\hline Region & $F$ & $\begin{array}{l}\text { 22q-del, } \\
\text { mean (SE) }\end{array}$ & $\begin{array}{l}\text { Control, } \\
\text { mean (SE) }\end{array}$ & $\begin{array}{l}\text { 22q-dup, } \\
\text { mean (SE) }\end{array}$ & Region & $F$ & $\begin{array}{l}\text { 22q-del, } \\
\text { mean (SE) }\end{array}$ & $\begin{array}{l}\text { Control, } \\
\text { mean (SE) }\end{array}$ & $\begin{array}{l}22 q \text {-dup, } \\
\text { mean (SE) }\end{array}$ \\
\hline Left hemisphere & & & & & Right hemisphere & & & & \\
\hline Bank of superior temporal sulcus & 3.0 & 1012.1 (19.2) & $1003.3(19.2)$ & $1092.9(33.8)$ & Bank of superior temporal sulcus & 2.3 & $944(15.2)$ & $991.3(15.3)$ & $996.9(26.8)$ \\
\hline Caudal anterior cingulate gyrus ${ }^{* *}, \dagger \dagger, \ddagger$ & 9.5 & $562.7(15.3)$ & $632.6(15.3)$ & $702.1(26.9)$ & Caudal anterior cingulate gyrus & 3.2 & $674.4(20.8)$ & $753.7(20.8)$ & $748.4(36.6)$ \\
\hline Caudal middle frontal gyrus & 1.6 & $2347.8(44.7)$ & $2229(44.8)$ & $2233.6(78.7)$ & Caudal middle frontal gyrus & 2.3 & $2122.7(47)$ & $1982.9(47.1)$ & $1943.2(82.7)$ \\
\hline Cuneus $^{* *}, \dagger, \dagger \dagger, \ddagger$ & 21.4 & $1207.1(24.6)$ & $1435.2(24.7)$ & $1477.9(43.4)$ & Cuneust,t†,‡ & 9.2 & $1315.4(21.9)$ & $1456.4(21.9)$ & $1444.3(38.5)$ \\
\hline Entorhinal cortex & 1.4 & $361(10.9)$ & $356.3(10.9)$ & $392(19.2)$ & Entorhinal cortex & 1.1 & $298.1(10)$ & $320.3(10)$ & $317.1(17.6)$ \\
\hline Frontal pole & 3.0 & $208(4.4)$ & $209.6(4.4)$ & $229.4(7.8)$ & Frontal pole & 4.0 & $280.2(6)$ & $286.3(6)$ & $315.4(10.5)$ \\
\hline Fusiform gyrus & 3.8 & $3089.4(42.8)$ & $3269.9(42.8)$ & $3223.2(75.3)$ & Fusiform gyrus & 1.7 & $3039.8(38.2)$ & $3147.4(38.3)$ & $3124.6(67.2)$ \\
\hline Inferior parietal cortex ${ }^{* *}, \dagger \dagger$ & 8.9 & $4753.7(55.1)$ & $4539.3(55.2)$ & $4257.6(97)$ & Inferior parietal cortex & 0.4 & $5522.2(71.2)$ & $5460(71.4)$ & $5386.2(125.4)$ \\
\hline Inferior temporal gyrus & 4.8 & $3060.1(42.8)$ & $3254.6(42.8)$ & $3126.8(75.3)$ & Inferior temporal gyrus & 1.1 & $3016.1(45.8)$ & $3063.2(45.8)$ & $2933.7(80.6)$ \\
\hline Insula†,†† & 12.9 & $2150.5(23.1)$ & $1972.2(23.1)$ & $2016.7(40.7)$ & Insulat,†† & 12.0 & $2188.7(31.5)$ & $1955.9(31.6)$ & $1985.6(55.5)$ \\
\hline Isthmus cingulate & 5.5 & $1035.8(18.7)$ & $962.9(18.7)$ & $1059.1(32.9)$ & Isthmus cingulate†, & 11.2 & $987.4(17.2)$ & $867.1(17.2)$ & $940.8(30.3)$ \\
\hline Lateral occipital cortex & 0.9 & $4603.4(58.5)$ & $4665(58.6)$ & $4773(102.9)$ & Lateral occipital cortex & 1.4 & $4513.9(61.4)$ & $4475.9(61.5)$ & $4302.8(108.1)$ \\
\hline Lateral orbitofrontal cortex ${ }^{* *}, t, \dagger$ & 12.7 & $2602.7(26.8)$ & $2422.1(26.8)$ & $2356.5(47.1)$ & Lateral orbitofrontal cortex ${ }^{* *}, \dagger, \dagger \dagger$ & 8.7 & $2504(32.2)$ & $2318.7(32.3)$ & $2267.5(56.8)$ \\
\hline Lingual gyrus**,, $, \dagger, \ddagger$ & 9.3 & $2691.7(45.2)$ & $2964.1(45.3)$ & $3028.9(79.6)$ & Lingual gyrus* ${ }^{*}, t, \dagger$ & 16.1 & $2663.8(41.4)$ & $3001.2(41.5)$ & $3046.4(72.9)$ \\
\hline Medial orbitofrontal cortex & 2.7 & $1712.5(26.2)$ & $1642(26.3)$ & $1739.3(46.2)$ & Medial orbitofrontal cortex & 2.2 & $1767.2(21.8)$ & $1711.4(21.8)$ & $1779.9(38.4)$ \\
\hline Middle temporal gyrus & 0.3 & $2947.1(35.8)$ & $2983.6(35.8)$ & $2953.5(62.9)$ & Middle temporal gyrus & 1.5 & $3349.2(36)$ & $3267.2(36)$ & $3231.7(63.3)$ \\
\hline Paracentral gyrus & 1.8 & $1311.3(20.5)$ & $1312(20.5)$ & $1384.8(36.1)$ & Paracentral gyrus & 0.2 & $1466.5(26.3)$ & $1479.2(26.3)$ & $1453.1(46.2)$ \\
\hline Parahippocampal gyrus & 1.6 & $735.3(15.4)$ & 705 (15.4) & $748.9(27.1)$ & Parahippocampal gyrus & 0.4 & $672.3(10.7)$ & $657.8(10.7)$ & $666.9(18.9)$ \\
\hline Pars opercularis & 3.3 & $1750.8(31.7)$ & $1639.5(31.7)$ & $1606.7(55.7)$ & Pars opercularis**,, , †† & 9.8 & $1458.5(25.4)$ & $1309.9(25.5)$ & $1249.2(44.8)$ \\
\hline Pars orbitalis & 4.1 & $641.3(10.1)$ & $598.3(10.2)$ & $599.6(17.8)$ & Pars orbitalis & 2.1 & $777.3(12.2)$ & $747.3(12.2)$ & $728.1(21.5)$ \\
\hline Pars triangularis & 0.0 & $1290.9(24.5)$ & $1287(24.6)$ & $1292.4(43.2)$ & Pars triangularis & 0.7 & $1425.3(28)$ & $1473.4(28)$ & $1474.5(49.2)$ \\
\hline Pericalcarine gyrust, & 8.3 & $1153.1(25.9)$ & $1308.5(25.9)$ & $1309.6(45.6)$ & Pericalcarine gyrus $t, \mathrm{t}, \ddagger$ & 10.2 & $1279.5(26)$ & $1458.4(26.1)$ & $1406.7(45.8)$ \\
\hline Postcentral gyrus & 0.1 & $4075.6(46.3)$ & $4093.8(46.4)$ & $4047.8(81.5)$ & Postcentral gyrus & 2.1 & $3845.7(48)$ & $3995.4(48.1)$ & $3957.2(84.5)$ \\
\hline Posterior cingulate & 1.5 & $1190(19.7)$ & $1174.1(19.8)$ & $1238.9(34.7)$ & Posterior cingulate & 0.0 & $1196.4(20.5)$ & $1189.4(20.5)$ & $1186.8(36)$ \\
\hline Precentral gyrust, $+\dagger$ & 14.8 & $5030.1(52)$ & $4604.7(52.1)$ & $4645.7(91.5)$ & Precentral gyrus ${ }^{* *}, \dagger, \mathrm{t}$ & 21.7 & $5049.7(45.9)$ & $4666.6(46)$ & $4468.5(80.8)$ \\
\hline Precuneus & 4.5 & $3542.2(43.8)$ & $3734(43.9)$ & $3745(77.1)$ & Precuneus & 2.5 & $3733.5(44.3)$ & $3791.4(44.4)$ & $3943.5(78)$ \\
\hline Rostral anterior cingulate & 6.8 & $729.4(15.5)$ & $750.5(15.5)$ & $848.3(27.2)$ & Rostral anterior cingulate & 2.5 & $638.4(15.5)$ & $632.6(15.6)$ & $699.4(27.3)$ \\
\hline Rostral middle frontal gyrus & 0.6 & $5387.4(61.3)$ & $5480.1(61.4)$ & $5389.1(108)$ & Rostral middle frontal gyrus & 3.1 & $5473.6(61.8)$ & $5704.7(61.9)$ & $5602.3(108.7)$ \\
\hline Superior frontal cortex & 2.3 & $7192.6(62)$ & $7030(62.1)$ & $6933.1(109.2)$ & Superior frontal cortex & 5.6 & $7073.8(62.7)$ & $6762.8(62.8)$ & $6762.4(110.4)$ \\
\hline Superior parietal cortex $\uparrow, \uparrow \dagger, \ddagger$ & 13.6 & $4941.4(66.6)$ & $5466.6(66.7)$ & $5233.2(117.2)$ & Superior parietal cortext, $\dagger+, \ddagger$ & 10.6 & $4952(62.1)$ & $5370.5(62.2)$ & $5395.4(109.4)$ \\
\hline Superior temporal gyrus & 6.4 & $3776(37.4)$ & $3585.7(37.5)$ & $3733.8(65.9)$ & Superior temporal gyrus & 1.3 & $3457.6(33.9)$ & $3429.4(34)$ & $3533.8(59.7)$ \\
\hline Supramarginal gyrus & 1.3 & $3933(54.4)$ & $3797.7(54.5)$ & $3822.2(95.8)$ & Supramarginal gyrus & 5.2 & $3682.6(52.9)$ & $3497(53)$ & $3775.3(93.1)$ \\
\hline Temporal pole & 3.7 & $442.6(7.5)$ & $472.7(7.5)$ & $472.6(13.2)$ & Temporal pole & 2.9 & $391.3(8.3)$ & $420.7(8.3)$ & 421.8 (14.6) \\
\hline Transverse temporal gyrus & 1.5 & $451.3(8.7)$ & $446.5(8.7)$ & $475.2(15.4)$ & Transverse temporal gyrus & 0.3 & $321.5(7)$ & $328.7(7)$ & $323.6(12.2)$ \\
\hline
\end{tabular}

${ }^{a}$ Adjusted means are covaried for age, sex, scanner location, and total area.

**Survives FDR correction ( $p<0.05$ threshold) at post hoc level for 22q-dup versus 22q-del.

†Survives FDR correction ( $p<0.05$ threshold) at post hoc level for 22q-del versus control.

t†Survives FDR correction ( $p<0.05$ threshold) at omnibus level.

fFDR-corrected omnibus effect as well as FDR-corrected del-dup or dup-con difference that remain significant with inclusion of total area covariate.

tively larger "hit" to SA and to global brain volume metrics than did duplications. This pattern is consistent with the relatively milder effect of 22q-dup on cognition, which aligns with epidemiological findings that duplication CNVs tend to have less deleterious effects on cognition (Männik et al., 2015). Widespread SA reductions in 22q-del, with more subtle increases for 22q-dup, may be a potential mechanism underlying differential deficits in cognition associated with deletions at this locus. However, regional CT decreases in 22q-dup were proportional to the increases observed in deletion carriers, albeit in somewhat different cortical regions.

While deletion-duplication differences in SA were widespread throughout the cortex, including frontotemporal regions critical for language (Friederici and Gierhan, 2013) and medial and lateral frontal and parietal regions implicated in self-referential thought and social perception (Kennedy and Adolphs, 2012), effects on CT were more localized. Despite the notable divergence in the specific brain regions predominantly affected by the deletion versus duplication, regions with the greatest magnitude of effects are notable in their shared role in social-cognitive neural circuitry (Lieberman, 2007; Adolphs, 2009).
The overall patterns detected in the cortex persisted into subcortical regions, previously shown to be affected by 22q-del (Bish et al., 2004; Kates et al., 2004), suggesting global effects of 22q11.2 $\mathrm{CNV}$ on brain development. Our novel shape analysis revealed localized patterns of subcortical alteration, which may correspond to underlying anatomic subfields that cannot be resolved by conventional volumetric approaches (Mamah et al., 2016). We found largely higher local thickness in 22q-dup relative to 22q-del carriers in bilateral hippocampal, left thalamus, and right amygdala structures; the opposite pattern was observed for bilateral putamen and caudate structures, which together form the dorsal striatum and importantly contain the same types of neurons and circuits (Alexander and Crutcher, 1990). Local and global hippocampal reductions in $22 \mathrm{q}$-del are consistent with findings in a mouse model, indicating decreased density of dendritic spines and glutamatergic synapses as well as impaired dendritic growth, in primary hippocampal neurons (Mukai et al., 2008). To our knowledge, no preclinical models of the reciprocal duplication have yet been developed; thus, it is unclear the extent to which our human findings are recapitulated in animal models. Future work aims to map known subfields to subcortical surface 
models so that stronger inferences may be made regarding the underlying compartmental effects detected by this shape analysis technique.

\section{Genes critical for cortical circuit formation in the 22q11.2 locus}

The 22q11.2 region houses many genes highly conserved in model organisms and expressed in the developing brain. Some 22q11.2 genes are selectively expressed in cortical progenitors in the ventricular/subventricular zones (e.g., ranbpl and $c d c 45 l$ ), whereas others, including $d g c r 8$, a microRNA processing cofactor, are more broadly expressed in cortical neurons (Meechan et al., 2015a). As many of these genes are expressed early in development, diminished dosage of multiple 22q11.2 genes may lead to compromised proliferative and neurogenic capacity of neuronal precursors.

Although the function of individual 22q11.2 genes in the developing cortex remains poorly understood, ranbp 1 gene dosage remains a candidate mechanism as a regulator of early nervous system development (Paronett et al., 2015). ranbp1 homozygous null mouse embryos are either exencephalic or microcephalic at early stages. ranbp 1 plays a role in rapidly dividing precursors in the developing cortex, loss of which may compromise the overall pool of cortical radial glial progenitors, resulting in a smaller brain. ranbp $1^{-1-}$ embryos were found to have selectively disrupted layer $2 / 3$ cortical projection neuron generation, suggesting an important role in cortical circuit development. In addition, a haplotype block including the ranbp1 and $d g c r 8$ genes was associated with idiopathic schizophrenia (Liu et al., 2002). Thus, targeted studies of the effects of overexpression and underexpression of Ranbp 1 and other key neurodevelopmental genes in the locus are warranted.

\section{Gene-dosage effects in other reciprocal CNVs}

Notably, dose-dependent effects of two other neuropsychiatric CNVs (15q11.2 BP1-BP2 and 16p11.2) on brain structure have recently been discovered. Our findings of similar diametric patterns in the 22q11.2 locus suggest that this anthropometric variation may be regulated by multiple, distinct genomic regions. Consistent with our 22q11.2 findings, in the Icelandic population Stefansson et al. (2014) found a positive gene dosage effect of $15 \mathrm{q} 11.2$ on gray matter volume, whereas corpus callosum size was lower in $15 \mathrm{q} 11.2$ duplication relative to deletion carriers. Further, convergent findings across 16p11.2 mouse and human studies indicate pervasive effects of gene dosage across cortical and subcortical structures, suggesting the role of genes important in early development (Horev et al., 2011; Qureshi et al., 2014). Similar to our results, reciprocal variation at $16 \mathrm{p} 11.2$ revealed widespread alterations in SA (Qureshi et al., 2014); intriguingly, however, the pattern of findings was in the opposite direction (deletion $>$ control $>$ duplication). Thus, while gene dosage is associated with opposing brain phenotypes across these "neuropsychiatric" CNVs, deletion or duplication of genomic material does not consistently determine the direction of effect. Finally, in a zebrafish model, Golzio et al. (2012) identified a single gene at the 16p11.2 locus, KCTD13, that is likely responsible for the opposing brain phenotypes, as it causes microcephaly when overexpressed and macrocephaly when suppressed. It is not yet known whether the patterns observed for 22q11.2 are attributable to a single gene or an oligogenic effect.

\section{Study limitations}

Several limitations of our study must be noted, such as the modest sample size of our 22q-dup group. As the first study to inves- tigate effects of reciprocal genomic variation in this region, these results should be confirmed in subsequent, larger investigations. Additionally, given the duplication's inheritance pattern (Wentzel et al., 2008), many participants in this group were related. Although effect sizes for our main findings did not substantively change when removing related individuals, we could not entirely disentangle familial effects from those of the duplication itself. Additionally, the two CNV groups contained a greater proportion of subjects of European ancestry than the control group; nevertheless, covarying for race did not alter the significant findings. Further, although 22q-dup carriers did not differ in nonverbal IQ from controls, it was not possible to match nonverbal IQ of duplication to deletion carriers. Crucially, however, our sample was highly representative of the phenotypic spectrum of 22q11.2 disorders in the broader population (McDonald-McGinn et al., 2015; Tang et al., 2016).

In conclusion, elucidating the pathophysiology of developmental neuropsychiatric disorders remains a major challenge, due to considerable heterogeneity at both the genetic and phenotypic level (Geschwind and Flint, 2015). The robust, opposing effects on brain structure described here highlight the utility of investigating the influence of reciprocal chromosomal imbalances on neural processes and how these may ultimately contribute to disease pathogenesis. Prospective longitudinal studies are underway to track divergent neurodevelopmental trajectories over time in CNV carriers. Finally, in vitro modeling of reciprocal CNVs at the 22q11.2 locus offers an avenue to directly characterize associated cellular phenotypes.

\section{References}

Adolphs R (2009) The social brain: neural basis of social knowledge. Annu Rev Psychol 60:693-716. CrossRef Medline

Alexander GE, Crutcher MD (1990) Functional architecture of basal ganglia circuits: neural substrates of parallel processing. Trends Neurosci 13:266271. CrossRef Medline

Bassett AS, Chow EW (2008) Schizophrenia and 22q11.2 deletion syndrome. Curr Psychiatry Rep 10:148-157. CrossRef Medline

Bearden CE, van Erp TG, Dutton RA, Tran H, Zimmermann L, Sun D, Geaga JA, Simon TJ, Glahn DC, Cannon TD, Emanuel BS, Toga AW, Thompson PM (2007) Mapping cortical thickness in children with 22q11.2 deletions. Cereb Cortex 17:1889-1898. CrossRef Medline

Benjamini Y, Hochberg Y (1995) Controlling the false discovery rate: a practical and powerful approach to multiple testing. J R Stat Soc B Met 57:289-300.

Bish JP, Nguyen V, Ding L, Ferrante S, Simon TJ (2004) Thalamic reductions in children with chromosome 22q11.2 deletion syndrome. Neuroreport 15:1413-1415. CrossRef Medline

CNV and Schizophrenia Working Groups of the Psychiatric Genomics Consortium, Psychosis Endophenotypes International Consortium (2017) Contribution of copy number variants to schizophrenia from a genomewide study of 41,321 subjects. Nat Genet 49:27-35. Medline

Constantino JN, Gruber CP (2007) Social Responsiveness Scale (SRS). Los Angeles: Western Psychological Services.

Coppola G, Choi SH, Santos MM, Miranda CJ, Tentler D, Wexler EM, Pandolfo M, Geschwind DH (2006) Gene expression profiling in frataxin deficient mice: microarray evidence for significant expression changes without detectable neurodegeneration. Neurobiol Dis 22:302-311. CrossRef Medline

Dale AM, Fischl B, Sereno MI (1999) Cortical surface-based analysis: I. Segmentation and surface reconstruction. Neuroimage 9:179-194. CrossRef Medline

Desikan RS, Ségonne F, Fischl B, Quinn BT, Dickerson BC, Blacker D, Buckner RL, Dale AM, Maguire RP, Hyman BT, Albert MS, Killiany RJ (2006) An automated labeling system for subdividing the human cerebral cortex on MRI scans into gyral based regions of interest. Neuroimage 31:968980. CrossRef Medline 
Ecker C, Ginestet C, Feng Y, Johnston P, Lombardo MV, Lai MC, Suckling J, Palaniyappan L, Daly E, Murphy CM, Williams SC, Bullmore ET, BaronCohen S, Brammer M, Murphy DG (2013) Brain surface anatomy in adults with autism: the relationship between surface area, cortical thickness, and autistic symptoms. JAMA Psychiatry 70:59-70. CrossRef Medline

Ensenauer RE, Adeyinka A, Flynn HC, Michels VV, Lindor NM, Dawson DB, Thorland EC, Lorentz CP, Goldstein JL, McDonald MT, Smith WE, Simon-Fayard E, Alexander AA, Kulharya AS, Ketterling RP, Clark RD, Jalal SM (2003) Microduplication 22q11.2, an emerging syndrome: clinical, cytogenetic, and molecular analysis of thirteen patients. Am J Hum Genet 73:1027-1040. CrossRef Medline

First MB, Gibbon M (2004) The Structured Clinical Interview for DSM-IV Axis I Disorders (SCID-I) and the Structured Clinical Interview for DSM-IV Axis II Disorders (SCID-II). In: Comprehensive handbook of psychological assessment, Vol. 2: Personality assessment (Hilsenroth MJ, Segal DL, eds), pp 134-143. Hoboken, NJ: Wiley.

Fischl B, Sereno MI, Dale AM (1999) Cortical surface-based analysis. II: Inflation, flattening, and a surface-based coordinate system. Neuroimage 9:195-207. CrossRef Medline

Friederici AD, Gierhan SM (2013) The language network. Curr Opin Neurobiol 23:250-254. CrossRef Medline

Geschwind DH, Flint J (2015) Genetics and genomics of psychiatric disease. Science 349:1489-1494. CrossRef Medline

Girirajan S, Brkanac Z, Coe BP, Baker C, Vives L, Vu TH, Shafer N, Bernier R, Ferrero GB, Silengo M, Warren ST, Moreno CS, Fichera M, Romano C, Raskind WH, Eichler EE (2011) Relative burden of large CNVs on a range of neurodevelopmental phenotypes. Plos Genet 7:e1002334. CrossRef Medline

Golzio C, Willer J, Talkowski ME, Oh EC, Taniguchi Y, Jacquemont S, Reymond A, Sun M, Sawa A, Gusella JF, Kamiya A, Beckmann JS, Katsanis N (2012) KCTD13 is a major driver of mirrored neuroanatomical phenotypes of the 16p11.2 copy number variant. Nature 485:363-367. CrossRef Medline

Grati FR, Molina Gomes D, Ferreira JC, Dupont C, Alesi V, Gouas L, HorelliKuitunen N, Choy KW, García-Herrero S, de la Vega AG, Piotrowski K, Genesio R, Queipo G, Malvestiti B, Hervé B, Benzacken B, Novelli A, Vago P, Piippo K, Leung TY, et al. (2015) Prevalence of recurrent pathogenic microdeletions and microduplications in over 9500 pregnancies. Prenatal Diag 35:801-809. CrossRef Medline

Green T, Gothelf D, Glaser B, Debbane M, Frisch A, Kotler M, Weizman A, Eliez S (2009) Psychiatric disorders and intellectual functioning throughout development in velocardiofacial (22q11.2 deletion) syndrome. J Am Acad Child Adolesc Psychiatry 48:1060-1068. CrossRef Medline

Gutman BA, Wang YL, Rajagopalan P, Toga AW, Thompson PM (2012) Shape matching with medial curves and 1-D group-wise registration, $\mathrm{pp}$ 716-719. 9th IEEE International Symposium on Biomedical Imaging, Barcelona, Spain, May 2-5, 2012.

Gutman BA, Jahanshad N, Ching CR, Wang YL, Kochunov PV, Nichols TE, Thompson PM (2015) Medial demons registration localizes the degree of genetic influence over subcortical shape variability: an $\mathrm{N}=1480$ metaanalysis. Proc EIII Int Symp Biomed Imaging 2015:1402-1406.

Hibar DP, et al. (2016) Subcortical volumetric abnormalities in bipolar disorder. Mol Psychiatry 21:1710-1716. CrossRef

Hiroi N, Takahashi T, Hishimoto A, Izumi T, Boku S, Hiramoto T (2013) Copy number variation at 22q11.2: from rare variants to common mechanisms of developmental neuropsychiatric disorders. Mol Psychiatry 18: 1153-1165. CrossRef

Hoeffding LK, Trabjerg BB, Olsen L, Mazin W, Sparsø T, Vangkilde A, Mortensen PB, Pedersen CB, Werge T (2017) Risk of psychiatric disorders among individuals with the 22q11.2 deletion or duplication: a Danish nationwide, register-based study. JAMA Psychiatry 74:282-290. CrossRef Medline

Horev G, Ellegood J, Lerch JP, Son YE, Muthuswamy L, Vogel H, Krieger AM, Buja A, Henkelman RM, Wigler M, Mills AA (2011) Dosage-dependent phenotypes in models of 16p11.2 lesions found in autism. Proc Natl Acad Sci U S A 108:17076-17081. CrossRef Medline

Jalbrzikowski M, Jonas R, Senturk D, Patel A, Chow C, Green MF, Bearden CE (2013) Structural abnormalities in cortical volume, thickness, and surface area in 22q11.2 microdeletion syndrome: relationship with psychotic symptoms. Neuroimage Clin 3:405-415. CrossRef Medline
Jalbrzikowski M, Ahmed KH, Patel A, Jonas R, Kushan L, Chow C, Bearden CE (2017) Categorical versus dimensional approaches to autismassociated intermediate phenotypes in 22q11.2 microdeletion syndrome. Biol Psychiatry Cogn Neurosci Neuroimaging 2:53-65. CrossRef Medline Kates WR, Burnette CP, Bessette BA, Folley BS, Strunge L, Jabs EW, Pearlson GD (2004) Frontal and caudate alterations in velocardiofacial syndrome (deletion at chromosome 22q11.2). J Child Neurol 19:337-342. CrossRef Medline

Kennedy DP, Adolphs R (2012) The social brain in psychiatric and neurological disorders. Trends Cogn Sci 16:559-572. CrossRef Medline

Lam KS, Aman MG (2007) The repetitive behavior scale-revised: independent validation in individuals with autism spectrum disorders. J Autism Dev Disord 37:855-866. CrossRef Medline

Li Z, Chen J, Xu Y, Yi Q, Ji W, Wang P, Shen J, Song Z, Wang M, Yang P, Wang Q, Feng G, Liu B, Sun W, Xu Q, Li B, He L, He G, Li W, Wen Z, et al. (2016) Genome-wide analysis of the role of copy number variation in schizophrenia risk in Chinese. Biol Psychiatry 80:331-337. CrossRef Medline

Lieberman MD (2007) Social cognitive neuroscience: a review of core processes. Annu Rev Psychol 58:259-289. CrossRef Medline

Liu H, Abecasis GR, Heath SC, Knowles A, Demars S, Chen YJ, Roos JL, Rapoport JL, Gogos JA, Karayiorgou M (2002) Genetic variation in the 22q11 locus and susceptibility to schizophrenia. Proc Natl Acad Sci U S A 99:16859-16864. CrossRef Medline

Lord C, Rutter M, Le Couteur A (1994) Autism diagnostic interview-revised: a revised version of a diagnostic interview for caregivers of individuals with possible pervasive developmental disorders. J Autism Dev Disord 24:659-685. CrossRef Medline

Lord C, Risi S, Lambrecht L, Cook EH Jr, Leventhal BL, DiLavore PC, Pickles A, Rutter M (2000) The Autism Diagnostic Observation Schedule-Generic: a standard measure of social and communication deficits associated with the spectrum of autism. J Autism Dev Disord 30:205-223. CrossRef Medline

Maillard AM, Ruef A, Pizzagalli F, Migliavacca E, Hippolyte L, Adaszewski S, Dukart J, Ferrari C, Conus P, Männik K, Zazhytska M, Siffredi V, Maeder P, Kutalik Z, Kherif F, Hadjikhani N, Beckmann JS, Reymond A, Draganski B, Jacquemont S (2015) The 16p11.2 locus modulates brain structures common to autism, schizophrenia and obesity. Mol Psychiatry 20: 140-147. CrossRef Medline

Malhotra D, Sebat J (2012) CNVs: harbingers of a rare variant revolution in psychiatric genetics. Cell 148:1223-1241. CrossRef Medline

Mamah D, Alpert KI, Barch DM, Csernansky JG, Wang L (2016) Subcortical neuromorphometry in schizophrenia spectrum and bipolar disorders. Neuroimage Clin 11:276-286. CrossRef Medline

Männik K, Mägi R, Macé A, Cole B, Guyatt AL, Shihab HA, Maillard AM, Alavere H, Kolk A, Reigo A, Mihailov E, Leitsalu L, Ferreira AM, Nõukas M, Teumer A, Salvi E, Cusi D, McGue M, Iacono WG, Gaunt TR, et al. (2015) Copy number variations and cognitive phenotypes in unselected populations. JAMA 313:2044-2054. CrossRef Medline

McDonald-McGinn DM, Sullivan KE, Marino B, Philip N, Swillen A, Vorstman JA, Zackai EH, Emanuel BS, Vermeesch JR, Morrow BE, Scambler PJ, Bassett AS (2015) 22q11.2 deletion syndrome. Nat Rev Dis Primers 1:15071. CrossRef Medline

Meechan DW, Maynard TM, Tucker ES, Fernandez A, Karpinski BA, Rothblat LA, LaMantia AS (2015a) Modeling a model: mouse genetics, 22q11.2 deletion syndrome, and disorders of cortical circuit development. Prog Neurobiol 130:1-28. CrossRef Medline

Meechan DW, Rutz HL, Fralish MS, Maynard TM, Rothblat LA, LaMantia AS (2015b) Cognitive ability is associated with altered medial frontal cortical circuits in the LgDel mouse model of 22q11.2DS. Cereb Cortex 25:11431151. CrossRef Medline

Mukai J, Dhilla A, Drew LJ, Stark KL, Cao L, MacDermott AB, Karayiorgou M, Gogos JA (2008) Palmitoylation-dependent neurodevelopmental deficits in a mouse model of 22q11 microdeletion. Nat Neurosci 11:13021310. CrossRef Medline

Niklasson L, Rasmussen P, Oskarsdóttir S, Gillberg C (2001) Neuropsychiatric disorders in the 22q11 deletion syndrome. Genet Med 3:79-84. CrossRef Medline

Niklasson L, Rasmussen P, Oskarsdóttir S, Gillberg C (2009) Autism, ADHD, mental retardation and behavior problems in 100 individuals with 22q11 deletion syndrome. Res Dev Disabil 30:763-773. CrossRef Medline 
Ohta H, Nordahl CW, Iosif AM, Lee A, Rogers S, Amaral DG (2016) Increased surface area, but not cortical thickness, in a subset of young boys with autism spectrum disorder. Autism Res 9:232-248. CrossRef Medline

Ou Z, Berg JS, Yonath H, Enciso VB, Miller DT, Picker J, Lenzi T, Keegan CE, Sutton VR, Belmont J, Chinault AC, Lupski JR, Cheung SW, Roeder E, Patel A (2008) Microduplications of 22q11.2 are frequently inherited and are associated with variable phenotypes. Genet Med 10:267-277. CrossRef Medline

Palaniyappan L, Mallikarjun P, Joseph V, White TP, Liddle PF (2011) Regional contraction of brain surface area involves three large-scale networks in schizophrenia. Schizophr Res 129:163-168. CrossRef Medline

Panizzon MS, Fennema-Notestine C, Eyler LT, Jernigan TL, Prom-Wormley E, Neale M, Jacobson K, Lyons MJ, Grant MD, Franz CE, Xian H, Tsuang M, Fischl B, Seidman L, Dale A, Kremen WS (2009) Distinct genetic influences on cortical surface area and cortical thickness. Cereb Cortex 19:2728-2735. CrossRef Medline

Paronett EM, Meechan DW, Karpinski BA, LaMantia AS, Maynard TM (2015) Ranbp1, deleted in DiGeorge/22q11.2 deletion syndrome, is a microcephaly gene that selectively disrupts layer $2 / 3$ cortical projection neuron generation. Cereb Cortex 25:3977-3993. CrossRef Medline

Qureshi AY, Mueller S, Snyder AZ, Mukherjee P, Berman JI, Roberts TP, Nagarajan SS, Spiro JE, Chung WK, Sherr EH, Buckner RL (2014) Opposing brain differences in $16 \mathrm{p} 11.2$ deletion and duplication carriers. J Neurosci 34:11199-11211. CrossRef Medline

R Core Team (2016) R: a language and environment for statistical computing. Vienna: R Foundation for Statistical Computing.

Rakic P (1988) Specification of cerebral cortical areas. Science 241:170-176. CrossRef Medline

Rakic P (1995) A small step for the cell, a giant leap for mankind: a hypothesis of neocortical expansion during evolution. Trends Neurosci 18:383388. CrossRef Medline

Raznahan A, Shaw P, Lalonde F, Stockman M, Wallace GL, Greenstein D, Clasen L, Gogtay N, Giedd JN (2011) How does your cortex grow? J Neurosci 31:7174-7177. CrossRef Medline

Rees E, Kirov G, Sanders A, Walters JT, Chambert KD, Shi J, Szatkiewicz J, O’Dushlaine C, Richards AL, Green EK, Jones I, Davies G, Legge SE, Moran JL, Pato C, Pato M, Genovese G, Levinson D, Duan J, Moy W, et al. (2014) Evidence that duplications of 22q11.2 protect against schizophrenia. Mol Psychiatry 19:37-40. CrossRef

Rees E, Kendall K, Pardiñas AF, Legge SE, Pocklington A, Escott-Price V, MacCabe JH, Collier DA, Holmans P, O'Donovan MC, Owen MJ, Walters JT, Kirov G (2016) Analysis of intellectual disability copy number variants for association with schizophrenia. JAMA Psychiatry 73:963969. CrossRef Medline

Roshchupkin GV, Gutman BA, Vernooij MW, Jahanshad N, Martin NG, Hofman A, McMahon KL, van der Lee SJ, van Duijn CM, de Zubicaray GI, Uitterlinden AG, Wright MJ, Niessen WJ, Thompson PM, Ikram MA, Adams HH (2016) Heritability of the shape of subcortical brain structures in the general population. Nat Commun 7:13738. CrossRef Medline

Schmaal L, Veltman DJ, van Erp TG, Sämann PG, Frodl T, Jahanshad N, Loehrer E, Tiemeier H, Hofman A, Niessen WJ, Vernooij MW, Ikram MA, Wittfeld K, Grabe HJ, Block A, Hegenscheid K, Völzke H, Hoehn D, Czisch M, Lagopoulos J, et al. (2016) Subcortical brain alterations in major depressive disorder: findings from the ENIGMA Major Depressive Disorder working group. Mol Psychiatry 21:806-812. CrossRef Medline

Schmitt JE, Vandekar S, Yi J, Calkins ME, Ruparel K, Roalf DR, Whinna D, Souders MC, Satterwaite TD, Prabhakaran K, McDonald-McGinn DM, Zackai EH, Gur RC, Emanuel BS, Gur RE (2015) Aberrant cortical morphometry in the 22q11.2 deletion syndrome. Biol Psychiatry 78:135-143. CrossRef Medline

Schneider M, Debbané M, Bassett AS, Chow EW, Fung WL, van den Bree M, Owen M, Murphy KC, Niarchou M, Kates WR, Antshel KM, Fremont W, McDonald-McGinn DM, Gur RE, Zackai EH, Vorstman J, Duijff SN, Klaassen PW, Swillen A, Gothelf D, et al. (2014) Psychiatric disorders from childhood to adulthood in 22q11.2 deletion syndrome: results from the International Consortium on Brain and Behavior in 22q11.2 Deletion Syndrome. Am J Psychiatry 171:627639. CrossRef Medline

Shaffer D, Fisher P, Lucas CP, Dulcan MK, Schwab-Stone ME (2000) NIMH Diagnostic Interview Schedule for Children Version IV (NIMH
DISC-IV): description, differences from previous versions, and reliability of some common diagnoses. J Am Acad Child Psychiatry 39:28-38. CrossRef Medline

Shaikh TH, O'Connor RJ, Pierpont ME, McGrath J, Hacker AM, Nimmakayalu M, Geiger E, Emanuel BS, Saitta SC (2007) Low copy repeats mediate distal chromosome 22q11.2 deletions: sequence analysis predicts breakpoint mechanisms. Genome Res 17:482-491. CrossRef Medline

Shaw P, Gogtay N, Rapoport J (2010) Childhood psychiatric disorders as anomalies in neurodevelopmental trajectories. Hum Brain Mapp 31:917925. CrossRef Medline

Shepherd AM, Laurens KR, Matheson SL, Carr VJ, Green MJ (2012) Systematic meta-review and quality assessment of the structural brain alterations in schizophrenia. Neurosci Biobehav Rev 36:1342-1356. CrossRef Medline

Small SA, Schobel SA, Buxton RB, Witter MP, Barnes CA (2011) A pathophysiological framework of hippocampal dysfunction in ageing and disease. Nat Rev Neurosci 12:585-601. CrossRef Medline

Sørensen KM, Agergaard P, Olesen C, Andersen PS, Larsen LA, Ostergaard JR, Schouten JP, Christiansen M (2010) Detecting 22q11.2 deletions by use of multiplex ligation-dependent probe amplification on DNA from neonatal dried blood spot samples. J Mol Diagn 12:147-151. CrossRef Medline

Stankiewicz P, Lupski JR (2002) Genome architecture, rearrangements and genomic disorders. Trends Genet 18:74-82. CrossRef Medline

Stefansson H, Meyer-Lindenberg A, Steinberg S, Magnusdottir B, Morgen K, Arnarsdottir S, Bjornsdottir G, Walters GB, Jonsdottir GA, Doyle OM, Tost H, Grimm O, Kristjansdottir S, Snorrason H, Davidsdottir SR, Gudmundsson LJ, Jonsson GF, Stefansdottir B, Helgadottir I, Haraldsson M, et al. (2014) CNVs conferring risk of autism or schizophrenia affect cognition in controls. Nature 505:361. Medline

Sullivan PF, Daly MJ, O'Donovan M (2012) Genetic architectures of psychiatric disorders: the emerging picture and its implications. Nat Rev Genet 13:537-551. CrossRef Medline

Tang SX, Moore TM, Calkins ME, Yi JJ, Savitt A, Kohler CG, Souders MC, Zackai EH, McDonald-McGinn DM, Emanuel BS, Gur RC, Gur RE (2016) The psychosis spectrum in 22q11.2 deletion syndrome is comparable to that of nondeleted youths. Biol Psychiatry. Advance online publication. Retrieved Sep 8, 2016. doi: 10.1016/j.biopsych.2016.08.034. CrossRef Medline

Thompson PM, Stein JL, Medland SE, Hibar DP, Vasquez AA, Renteria ME, Toro R, Jahanshad N, Schumann G, Franke B, Wright MJ, Martin NG, Agartz I, Alda M, Alhusaini S, Almasy L, Almeida J, Alpert K, Andreasen NC, Andreassen OA, et al. (2014) The ENIGMA Consortium: largescale collaborative analyses of neuroimaging and genetic data. Brain Imaging Behav 8:153-182. Medline

Thompson PM, Andreassen OA, Arias-Vasquez A, Bearden CE, Boedhoe PS, Brouwer RM, Buckner RL, Buitelaar JK, Bulayeva KB, Cannon DM, Cohen RA, Conrod PJ, Dale AM, Deary IJ, Dennis EL, de Reus MA, Desrivieres S, Dima D, Donohoe G, Fisher SE, et al. (2017) ENIGMA and the individual: predicting factors that affect the brain in 35 countries worldwide. Neuroimage 145:389-408. CrossRef Medline

van Erp TG, Hibar DP, Rasmussen JM, Glahn DC, Pearlson GD, Andreassen OA, Agartz I, Westlye LT, Haukvik UK, Dale AM, Melle I, Hartberg CB, Gruber O, Kraemer B, Zilles D, Donohoe G, Kelly S, McDonald C, Morris DW, Cannon DM, et al. (2016) Subcortical brain volume abnormalities in 2028 individuals with schizophrenia and 2540 healthy controls via the ENIGMA consortium. Mol Psychiatry 21:547-553. CrossRef Medline

Ventura J, Liberman RP, Green MF, Shaner A, Mintz J (1998) Training and quality assurance with the Structured Clinical Interview for DSM-IV (SCID-I/P). Psychiatry Res 79:163-173. CrossRef Medline

Vorstman JA, Morcus ME, Duijff SN, Klaassen PW, Heineman-de Boer JA, Beemer FA, Swaab H, Kahn RS, van Engeland H (2006) The 22q11.2 deletion in children: high rate of autistic disorders and early onset of psychotic symptoms. J Am Acad Child Adolesc Psychiatry 45:1104-1113. CrossRef Medline

Wallace GL, Eisenberg IW, Robustelli B, Dankner N, Kenworthy L, Giedd JN, Martin A (2015) Longitudinal cortical development during adolescence and young adulthood in autism spectrum disorder: increased cortical 
thinning but comparable surface area changes. J Am Acad Child Psychiatry 54:464-469. CrossRef Medline

Wang L, Mamah D, Harms MP, Karnik M, Price JL, Gado MH, Thompson PA, Barch DM, Miller MI, Csernansky JG (2008) Progressive deformation of deep brain nuclei and hippocampal-amygdala formation in schizophrenia. Biol Psychiatry 64:1060-1068. CrossRef Medline

Wechsler D (1999) WASI manual. San Antonio: Psychological Corporation.

Wechsler D, Coalson DL, Raiford SE (2008) WAIS-IV: Wechsler Adult Intelligence Scale. San Antonio: Pearson.

Wenger TL, Miller JS, DePolo LM, de Marchena AB, Clements CC, Emanuel BS, Zackai EH, McDonald-McGinn DM, Schultz RT (2016) 22q11.2 duplication syndrome: elevated rate of autism spectrum disorder and need for medical screening. Mol Autism 7:27. CrossRef Medline
Wentzel C, Fernström M, Ohrner Y, Annerén G, Thuresson AC (2008) Clinical variability of the 22q11.2 duplication syndrome. Eur J Med Genet 51:501-510. CrossRef Medline

Wierenga LM, Langen M, Oranje B, Durston S (2014) Unique developmental trajectories of cortical thickness and surface area. Neuroimage 87:120 126. CrossRef Medline

Winkler AM, Kochunov P, Blangero J, Almasy L, Zilles K, Fox PT, Duggirala R, Glahn DC (2010) Cortical thickness or grey matter volume? The importance of selecting the phenotype for imaging genetics studies. Neuroimage 53:1135-1146. CrossRef Medline

Yu S, Cox K, Friend K, Smith S, Buchheim R, Bain S, Liebelt J, Thompson E, Bratkovic D (2008) Familial 22q11.2 duplication: a three-generation family with a $3-\mathrm{Mb}$ duplication and a familial $1.5-\mathrm{Mb}$ duplication. Clin Genet 73:160-164. CrossRef Medline 